\title{
Avaliação térmica, física e mecânica de blocos de concreto com poliestireno expandido reciclado
}

\author{
Thermal, physical and mechanical evaluation of concrete
} blocks with recycled expanded polystyrene

\section{Paulo Gonçalves Raimundo Vasconcelos}

\section{Resumo}

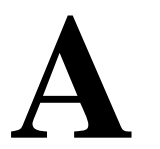

presente pesquisa produziu blocos de concretos com substituição parcial do agregado graúdo comumente utilizado por poliestireno expandido reciclado. Para tanto, uma dosagem experimentalé proposta a partir da associação do modelo de empacotamento compressível com a metodologia adaptada de Tango, publicada em 1994, produzindo-se quatro tipos de blocos (um referencial sem substituição e três com substituição volumétrica de $5 \%, 10 \%$ e $15 \%$ do agregado pelo poliestireno expandido), com fator a/c igual a 0,5 . As características físicas e mecânicas foram obtidas em conformidade com a NBR 12118:2013, identificando-se que os blocos referenciais e com 5\% de substituição poderiam ser empregados para fins estruturais, enquanto aqueles com $10 \%$ e $15 \%$ de substituição não alcançaram a resistência mínima estabelecida pela NBR 6136:2016. A análise do desempenho térmico adotou procedimentos de cálculo da NBR 15220-2:2005, verificando-se os limites estabelecidos pela NBR 15575-4:2013. O conforto térmico proporcionado pelos blocos referenciais e com 15\% de substituição, em protótipos de alvenaria, apresentaram resultados semelhantes para temperaturas internas durante o período observado. Contudo, no horário de pico da temperatura ambiente, verificaram-se maiores atrasos e inércia térmica na alvenaria com poliestireno reciclado.

Palavras-chave: Materiais alternativos. Termografia. Concreto com EPS.

\begin{abstract}
The research project produced concrete blocks with partial replacement of traditional coarse aggregate by recycled expanded polystyrene. Hence, an experimental dosage was proposed, associating the Compressible Packaging Model with Tango's adapted methodology, published in 1994, to produce four types of blocks (one reference, without substitution, and three with content ratios of 5, 10 and 15\% of partial volumetric replacement of coarse aggregate by expanded polystyrene), with a w/c ratio of 0,5 . Tests were performed to check the physical and mechanical characteristics of the blocks, following NBR 12118:2013, demonstrating that the reference block and the one with 5\% coarse aggregate partial replacement could be used for structural applications, while the blocks with 10 and 15\% partial replacement did not meet the NBR 6136:2016 standard for minimum compressive strength. The analysis of the thermal performance of the blocks was done using the calculation procedures of NBR 15220-2:2005, verifying the limits established by NBR 15575-4:2013. The thermal comfort provided by the reference blocks and the blocks with 15\% replacement in the masonry prototypes presented similar internal temperature results during the observed period. However, at times when the highest environment temperatures were recorded, the masonry with recycled polystyrene presented maximum delay and thermal inertia.
\end{abstract}

Recebido em 02/06/18 Aceito em 19/01/19 Keywords: Alternative materials. Thermography. Concrete with EPS. 


\section{Introdução}

O poliestireno expandido é um polímero termoplástico obtido pelo processo de expansão do poliestireno por pentano (SARTORTI, 2015). Conhecido também pela sigla inglesa EPS, essematerial apresenta como principais propriedades, segundo Ferrándiz-Mas e GarcíaAlcocel (2012), baixa condutividade térmica, baixo peso específico (entre $10 \mathrm{~kg} / \mathrm{m}^{3}$ e $30 \mathrm{~kg} / \mathrm{m}^{3}$ ), baixa absorção de água, além de ser sustentável devido a sua reciclagem.

A prática da reciclagemde embalagens descartadas de poliestireno expandido é encontrada no Polo Industrial de Manaus (PIM), segundoVieira et al. (2016), reincorporando-as em novos produtos utilizados nos mais diversos setores, e na construção civilesses materiais são empregados comumente como agregados leves de concreto.

Desde a publicação de Cook (1973), houve o desenvolvimento de pesquisas voltadas para produção de concretos com EPS. O EPS é utilizado na substituição volumétrica parcial dos agregados, em virtude de sua inércia e granulometria semelhante.O concreto com EPS, de acordo com Catóia (2012), atua como um incorporador de ar, contribuindo para a isolação térmica de suas estruturas, fazendo parte da classe dos concretos leves com porosidade presente nos agregados. Normalmente adicionam-se, segundo Mandlik et al. (2015), Liu e Chen (2013), Kaya e Kar (2016) Ferrándiz-Mas e García-Alcocel (2012), outros aditivos como os superplastificantes, resinas, pozolanas e incorporadores de ar para otimização das propriedades mecânicas e físicas do concreto com EPS.

Em publicações como a do Comité EuroInternational du Béton and Fédération Internationale de la Précontrainte (COMITÉ..., 1977) e ACI 211.2 (AMERICAN..., 1998), encontram-se especificações quanto à dosagem de concretos mais leves. O estudo do empacotamento das partículas também exerce, segundo Catóia (2012) e Neville (2016), importância fundamental nesse concreto, pois aumenta a coesão e a resistência, reduz a segregação e exsudação, e diminui o consumo de cimento.

Catóia (2012) afirma que a produção do concreto com EPS adota procedimentos semelhantes aos empregados para o concreto usual, ao minimizar problemas de infraestrutura e técnicas específicas voltadas a sua produção. Contudo, assim como os outros concretos, existem cuidados referentes à introdução do EPS na mistura, segundo Tang, Cui e Tahmasbi (2016), adotando aditivos que o revistam quimicamente para evitar sua segregação na massa.
A redução do peso específico das estruturas com concreto leve é obtida em função da realização do controle na granulometria do polímero termoplástico (CATÓIA, 2012). Melhorias ao ataque químico e à corrosão das armaduras internas do concreto também são observadas, segundo Sayadi et al. (2016), quando se substitui o agregado natural, leve ou usual, por amostras de poliestireno expandido reciclado.

Neville (2016) ressalta que o elevado volume de vazios existentes nos concretos com poliestireno expandido agrega benefícios como o aumento da capacidade de absorção térmica e redução da transferência de calor, em virtude de sua baixa condutividade, o que proporciona maior isolação ao concreto.

Os resultados obtidos por Monte, Bamonte e Gambarova (2015) indicam a redução da condutividade térmica para concretos com EPS apenas para temperaturas acima de $300^{\circ} \mathrm{C}$, pois os espaços inicialmente ocupados pelos grânulos ficaram vazios, aumentando a porosidade do concreto. Xu et al. (2016) acrescenta que a condutividade foi independente do fator a/c para amostras que substituíram $40 \%$ dos agregados por pérolas de $3 \mathrm{~mm}$ de diâmetro, com relação água/cimento de 0,45. Todavia, a composição granulométrica, o teor de umidade, a densidade, a temperatura, a cura e a compactação do concreto interfeririam nessa propriedade térmica. Demirboga e Kan (2012) estabeleceram uma relação direta entre o teor de EPS utilizado no concreto e capacidade de isolação térmica proporcionada a ele, com aumento de até $70 \%$ quando se empregou o resíduo de EPS.

O concreto com poliestireno expandido pode ser utilizado tanto para fins estruturais quanto apenas de vedação, encontrando nos blocos uma de suas aplicações.Os blocos de concreto surgem como opção à alvenaria tradicional, ao reduzir o consumo de energia e combustíveis fósseis durante a sua fabricação (LING; TEO, 2013). Todavia, existem poucas publicações de pesquisas com o emprego de EPS para essa finalidade.

Nesse contexto, o trabalho de $\mathrm{Xu}$ et al. (2012) estudou a resistência à compressão axial e a dosagem ideal dos blocos para o uso desse polímero como resíduos, alémda resistência cisalhante, os fatores que afetam a densidade dos blocos e a relação entre essas propriedades. Ling e Teo (2013) incorporaram cinza da casca do arroz em distintas proporções na composição de blocos com fator a/c $(0,5)$ e volume de EPS $\left(219 \mathrm{~kg} / \mathrm{m}^{3}\right)$ constantes, percebendo que essas adições interferiram na 
trabalhabilidade, no teor de ar presente e na densidade dos concretos.

O estudo de Hernández-Zaragoza et al. (2013) abordou a pré-saturação do poliestireno reciclado para produção de blocos celulares, e da sua relação com a umidade existente no local de estudo, constatando-se que a umidade do EPS interferiu negativamente na resistência das amostras, aumentando a densidade e absorção. Demirel (2013) estudou a influência do tamanho dos blocos compostos depedra-pomes e EPS na resistência mecânica e na transferência de calor, definindo as espessuras de $40 \mathrm{~mm}$ para menor taxa de transmissão de calor e $20 \mathrm{~mm}$ para máxima capacidade compressiva.

Em função dos fatores mencionados, buscou-se determinar o teor de substituição ideal do agregado graúdo tradicional por EPS reciclado para produção de blocos vazados de concreto.Logo, desenvolveuse um procedimento de dosagem experimental que possibilitasse atingir esseobjetivo, tendo em vista que as metodologias usuais para obtenção de concretos não conduziam a uma mistura que pudesse ser empregada para a produção dos blocos, e àquela proposta por Tango (1994), comumente empregada para essa finalidade, não possuía, a priori, argumentos científicos para sua utilização.

\section{Materiais e métodos}

\section{Materiais}

Os materiais utilizados para a moldagem dos blocos foram cimento do tipo CP I-S 40, areia de rio peneirada com dimensão máxima característica (DMC) e módulo de finura (MF) iguais a 1,19 mm e 2,58, respectivamente, e massa específica de $2.617 \mathrm{~kg} / \mathrm{m}^{3}$, brita de origem granítica (DMC $=9,5$ $\mathrm{mm})$ com massa específica de $2.717 \mathrm{~kg} / \mathrm{m}^{3}$ e grânulos de EPS reciclados (DMC $=12,5 \mathrm{~mm}$ ) com massa específica de $1.006 \mathrm{~kg} / \mathrm{m}^{3}$. O EPS reciclado (Figura 1) é oriundo de uma indústria do PIM, que processa mecanicamente o material a partir de embalagens descartadasde poliestireno expandido.

\section{Dosagem experimental}

Os procedimentos e ensaios referentes à dosagem experimental desenvolvida na pesquisa estão descritos no fluxograma da Figura 2.

A parte prática da dosagem experimental, que se refere à caracterização física dos materiais utilizados para produção dos blocos, está descrita detalhadamente em Gonçalves (2018). Contudo, destaca-se que a análise granulométrica do cimento foi executada em um equipamento da marca Malvern, modelo Mastersize 2000. Em relação à determinação da compacidade real, foram adotados dois processos distintos em função da granulometria dos materiais: o ensaio de demanda de água para o cimento e o de vibrocompressão para os agregados.

A execução do ensaio de demanda de água seguiu as etapas descritas por Formagini (2005), em função do consumo de água necessário da pasta para determinação da compacidade real do cimento. A compacidade obtida pelo ensaio de demanda de águaé calculada por meio da Equação 1.

$\mathrm{C}=\frac{1}{1+\mathrm{m}_{\mathrm{e}} \cdot \frac{\mathrm{M}_{\mathrm{H}_{2} \mathrm{O}}}{\mathrm{M}}}$

Eq. 1

Onde:

C - compacidade experimental do cimento;

$\mathrm{m}_{\mathrm{e}}$ - massa específica do material $\left(\mathrm{g} / \mathrm{cm}^{3}\right)$;

$\mathrm{M}_{\mathrm{H} 20}$ - massa de água total na mistura (g); e

M - massa do material (g).

A determinação da compacidade real dos agregados também obedeceu às recomendações de Formagini $(2005)^{1}$, empregando-se um cilindro padronizado e uma mesa vibratória para o ensaio (Figura 3).

Ao aferir a camada compactada do agregado, determinou-se sua compacidade real com o emprego da Equação 2.

$\mathrm{C}=\frac{4 \mathrm{M}_{\mathrm{s}}}{\pi \mathrm{D}_{\mathrm{C}}^{2} \mathrm{~h} \rho_{\mathrm{s}}}$

Eq. 2

Onde:

C - compacidade do agregado;

$\mathrm{M}_{\mathrm{s}}$ - massa do material seco (g);

$\mathrm{D}_{\mathrm{c}}$ - diâmetro interno do cilindro (cm);

$\mathrm{h}$ - altura final da camada compactada (cm); e

$\rho_{\mathrm{s}}$ - densidade do material $\left(\mathrm{g} / \mathrm{cm}^{3}\right)$.

Em relação aos princípios teóricos para dosagem experimental aqui proposta, esses são baseados nomodelo de empacotamento compressível (MEC), o qual foi desenvolvido por De Larrard (1999) visa, segundo Formagini (2005), à máxima compacidade de grãos em função de dois segmentos: pelo empacotamento virtual e por procedimentos físicos de compactação dependente da granulometria trabalhada, relacionando-os por meio de um índice de compactação $\left(\mathrm{K}_{\mathrm{c}}\right)$. 
Figura 1 - Grânulos de EPS reciclado empregados na pesquisa

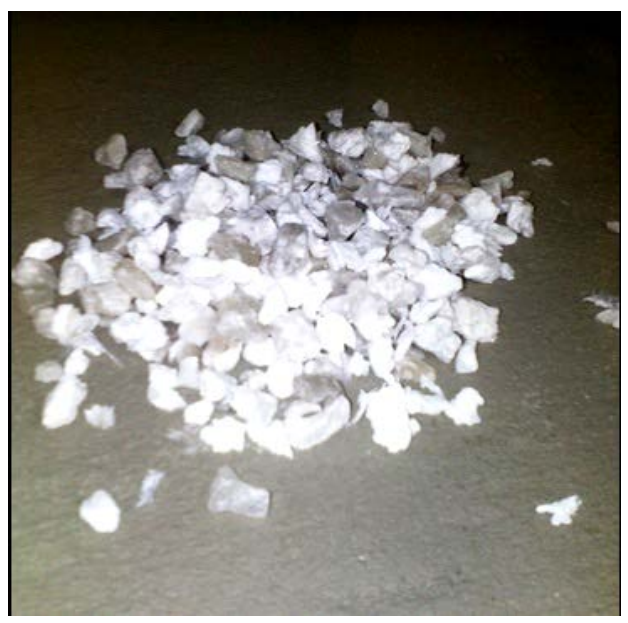

Figura 2 - Fluxograma para a dosagem experimental dos blocos empregada na pesquisa

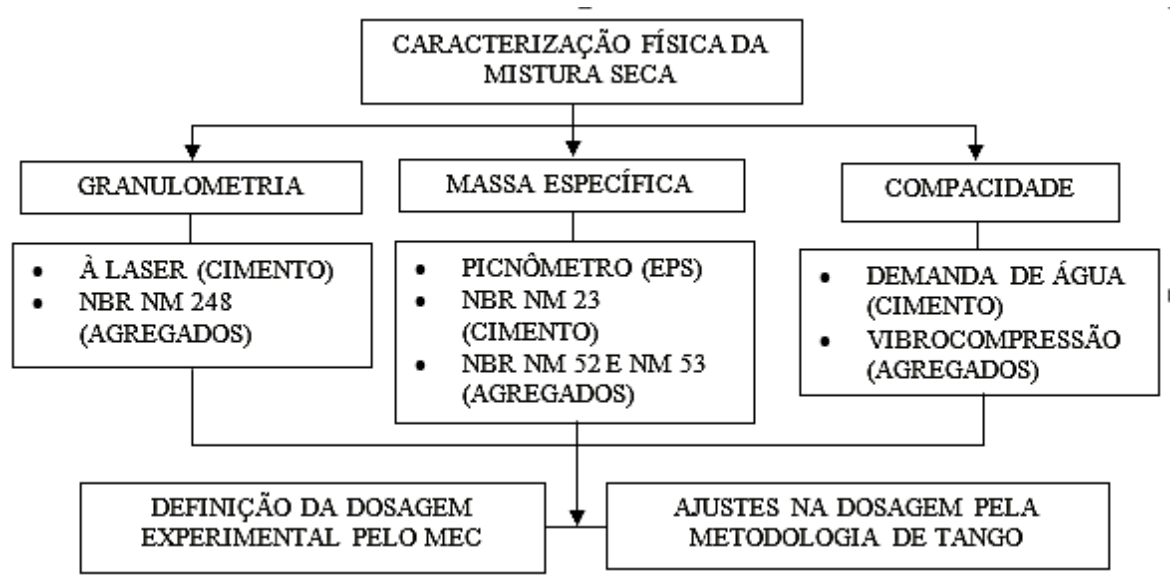

Fonte: Associação Brasileira de Normas Técnicas (2001, 2003, 2009a, 2009b).

Figura 3 - Equipamentos para o ensaio de compacidade real dos agregados

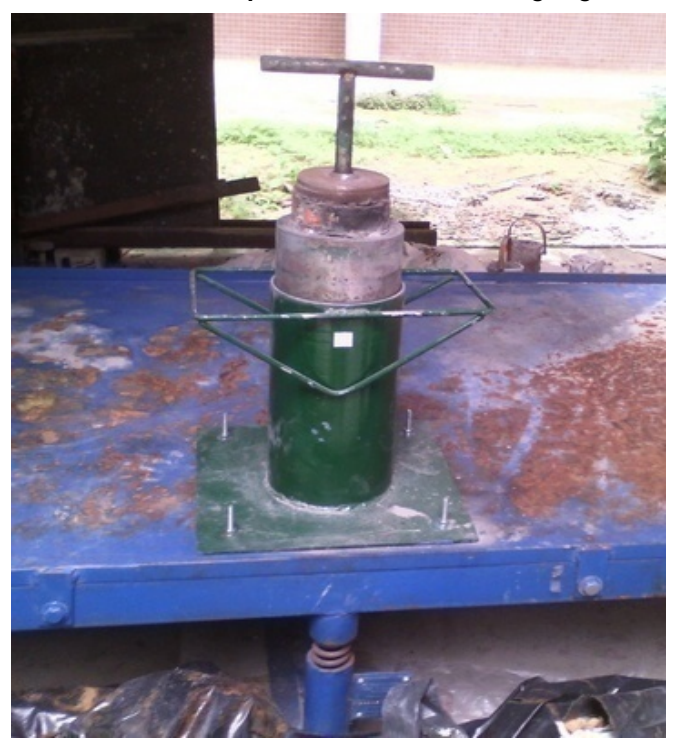


O MEC, de acordo com Formagini (2005), pode ser empregado para a determinação das frações volumétricas ou em massa que apresentem o maior empacotamento das partículas de "M" materiais compostos por " $n$ " classes cada um. Para isso, considera-se a quantidade de classes (faixas de tamanhos das partículas) fixa e preenchidas por composições distintas. De posse desses dados, calcula-se a compacidade virtual por meio daEquação 3.

$$
\begin{gathered}
\gamma^{(\mathrm{m}, \mathrm{i})}=\frac{\beta_{\mathrm{mi}}}{1-\sum_{\mathrm{k}=1}^{\mathrm{M}}\{\alpha+\delta\}} \\
\alpha=\sum_{\mathrm{j}=1}^{\mathrm{i}}\left[1-\beta_{\mathrm{mi}}+\mathrm{b}_{\mathrm{ij}} \beta_{\mathrm{mi}}\left(1-\frac{1}{\beta_{\mathrm{kj}}}\right) \mathrm{p}_{\mathrm{k}} \mathrm{y}_{\mathrm{kj}}\right] \\
\delta=\sum_{\mathrm{j}=\mathrm{i}+1}^{\mathrm{N}}\left[1-\mathrm{a}_{\mathrm{ij}}\left(\frac{\beta_{\mathrm{mi}}}{\beta_{\mathrm{kj}}}\right) \mathrm{p}_{\mathrm{k}} \mathrm{y}_{\mathrm{kj}}\right]
\end{gathered}
$$

Onde:

$\gamma$ - compacidade virtual da mistura;

y- fração volumétrica da classe;

i - classe adotada;

m, k - materiais utilizados;

$\beta$ - compacidade virtual de classe;

a - coeficiente do efeito de afastamento entre os grãos de classe distinta; e

b - coeficiente do efeito de parede entre os grãos de classe distinta.

Os coeficientes mencionados na Equação 3 se relacionam aos efeitos de afastamento dos grãos e de parede, e são determinados pelas Equações 4 e 5.

$\mathrm{a}_{\mathrm{ij}}=\sqrt{\left[1-\left(1-\frac{\mathrm{d}_{\mathrm{i}}}{\mathrm{d}_{\mathrm{j}}}\right)^{1,02}\right]}$
$\mathrm{b}_{\mathrm{ij}}=\sqrt{\left[1-\left(1-\frac{\mathrm{d}_{\mathrm{i}}}{\mathrm{d}_{\mathrm{j}}}\right)^{3}\right]}$

Onde:

d - dimensão das partículas; e

i,j - classes de interação.

As compacidades reais dos materiais (com exceção do EPS) foram obtidas pelos procedimentos práticos descritos por Formagini (2005). Contudo, o autor destaca que, para misturas polidispersas, a Equação 6 é adotada para a função dessa propriedade.

$\mathrm{f}(\varnothing)=\sum_{\mathrm{i}=1}^{\mathrm{M}} \sum_{\mathrm{m}=1}^{\mathrm{M}} \frac{\frac{\mathrm{p}_{\mathrm{m}} \mathrm{y}_{\mathrm{mi}}}{\beta_{\mathrm{mi}}}}{\frac{1}{\varnothing}-\frac{1}{\gamma^{(\mathrm{i})}}}-\mathrm{K}_{\mathrm{c}}=0$

Para calcular o índice que correlaciona as duas compacidades emprega-se a Equação 7.

$\mathrm{K}_{\mathrm{c}}=\sum_{\mathrm{i}=1}^{\mathrm{M}} \sum_{\mathrm{m}=1}^{\mathrm{M}} \frac{\frac{\mathrm{p}_{\mathrm{m}} \mathrm{y}_{\mathrm{mi}}}{\beta_{\mathrm{mi}}}}{\frac{1}{\bar{\sigma}}-\frac{1}{\gamma^{(\mathrm{i})}}}=0$

Onde:

$\phi$ - compacidade real;

$\mathrm{K}_{\mathrm{c}}$ - índice de compactação; e

$\mathrm{M}$ - número de materiais.

De possede todos os dados obtidos experimentalmentepelo emprego das equações (1) a (7) em um software, foi obtida a composição ideal para a produção de um metro cúbico de concreto. Em seguida, fez-se o ajuste dessa composição utilizando a metodologia adaptada de Tango (1994) em conformidade com o trabalho de Almeida, Sousa e Lima (2012) em função do mau acabamento dos blocos obtidos pelo emprego da dosagem obtida somente pelo MEC. Identificou-se que a razão para isso foi à proporção entre os agregadosempregados inicialmente, que favorecia a presença de vazios na superfície das paredes dos blocos.

Logo, utilizando-se da metodologia de Tango (1994), buscou-seaferir opercentual de cada agregado, partindo-se de $100 \%$ de brita e $0 \%$ de areia, com a retirada do primeiro e acréscimo do segundo em mesma proporção percentual, de modo a possibilitar a maior massa unitária da misturadessescomponentes. Com isso, redefiniu-se a composição volumétricacom percentualde $45 \%$ para a areia e $55 \%$ para a brita, obtendo-se a composição da mistura seca discriminada na Tabela 1.Contudo, destaca-se que apesar do MEC produzir um traço que favoreça a moldagem dos blocos, adotou-se a combinação dessa metodologia com a de Tango (1994) por produzir uma argamassa capaz de envolver maior quantidade de agregados graúdos, evitando a segregação. 
Tabela 1 - Dosagem experimental dos blocos de concreto, com valores em $\mathbf{~ k g / \mathbf { m } ^ { 3 }}$
BREF - bloco de referência (sem a presença de EPS reciclado);
B5 - bloco com substituição parcial de 5\%da brita por EPS reciclado;
B10 - bloco com substituição parcial de $10 \%$ da brita por EPS reciclado; e
B15 - bloco com substituição parcial de 15\% da brita por EPS reciclado.

Nota: Legenda:

\begin{tabular}{c|c|c|c|c}
\hline Tipo de Bloco & Cimento & Areia & Brita & EPS \\
\hline BREF & 241,78 & 829,30 & 1013,06 & - \\
B5 & 241,78 & 829,30 & 962,41 & 9,38 \\
B10 & 241,78 & 829,30 & 911,76 & 18,76 \\
B15 & 241,78 & 829,30 & 861,12 & 28,14 \\
\hline
\end{tabular}

A determinação do teor de umidade ótima dos blocos, ainda segundo Tango (1994), consiste em descobrir, através da introdução de pequenas quantidades de água na mistura seca, uma consistência propícia a moldagem de uma pelota de massa na mão, sem sujá-la consideravelmente (excesso de água), estabelecendo assim o fator a/c para a mistura seca de 0,5 . Por ser um procedimento empírico, houve a avaliação da consistência dos blocos por meio do ensaio da NBR NM 67 (ABNT, 1998), empregado para determinação da consistência em concretos plásticos, obtendo-se um abatimento nulo para os quatro tipos de blocos (Figura 4), o que, segundo Soto (2017), viabiliza o concreto ser vibrocompactado.Contudo, salienta-se que o concreto produzido não se enquadra no grupo dosque obedecem à Lei de Abrams, o que inviabiliza a substituição da metodologia de Tango (1994) pelo ensaio de consistência com cone de Abrams.

\section{Produção dos blocos}

Os materiais foram pesadossegundoos valores apresentados na Tabela 1. Após a pesagem, os componentes foram misturados em uma betoneira com capacidade nominal de 400 litros, por aproximadamente cinco minutos para homogeneização da mistura. Destaca-se que não houvea utilização de aditivos químicos que melhorassem a aderência do EPS reciclado com a matriz cimentícia. Após a mistura, utilizou-se uma vibroprensa, da marca Atlântica Maq, para produção de blocoscom dimensões de $190 \mathrm{~mm} \mathrm{x}$ 390 mm x 190 mm.

A cura ocorreu a temperatura ambiente (30,5 \pm 2 $\left.{ }^{\circ} \mathrm{C}\right)$, seguindo o processo produtivogeralmente empregado na região(sem umedecimentodos blocosdevido à alta umidade local)e estocando-os em locais livres de correntes de ar e sem a ação direta do sol, em funçãodas recomendações de Tango (1984).

\section{Ensaios mecânico e físicosdos blocos}

Os ensaios padronizados para os blocos vazados de concreto obedeceram às diretrizes da NBR 12118 (ABNT, 2013a) (análoga a ASTM C140/C140M (AMERICAN..., 2014b)). A amostragem para o ensaio e a equação para determinação da resistência característica estão em conformidade com os itens 6.3 (Tabela 4) e 6.5.2 da NBR 6136 (ABNT, 2016), respectivamente. Tango (1984) também adotou essa equação para determinação dessapropriedade mecânica. Empregou-se ainda a análise de variância (ANOVA) para verificar a influência dos teores de EPS na resistência à compressão dos blocos, adotando-se probabilidade de $95 \%$ de confiança e a hipótese nula para influência do teor de EPS para significâncias acima de 5\% (p-valor $\geq 0,05$ ).

Além disso, com o objetivo deavaliarda resistência à compressão do concreto produzido nesta pesquisa, foram moldados corpos de prova cilíndricos conforme a NBR 5738 (ABNT, 2015), que após 28 dias de cura úmida foram submetidos ao ensaio de compressão simples segundoas diretrizes da NBR 5739 (ABNT, 2007).

Para o capeamento adotado na regularização das superfícies dos blocos para o ensaio de resistência à compressão axial foi empregada argamassa com traço 1:3 (cimento:areia). O equipamento utilizado foi uma prensa hidráulica, da marca Tokyo Testing Machine, com célula de carga de $100 \mathrm{kN}$, a uma taxa de carregamento de $0,02 \mathrm{MPa} / \mathrm{s}$.O ensaio de resistência ocorreu após os 28 dias de cura ao ar.

As aferições dos pesos seco, saturado e referente às condições dosblocos submetidos a compressão ocorreram para determinaçãodos teores de absorção e umidade relativa em conformidade com a NBR 12118 (ABNT, 2013a). 
Figura 4 - Abatimentos de tronco de cone para os quatro tipos de blocos: (a) BREF, (b) B5, (c) B10, (d) B15

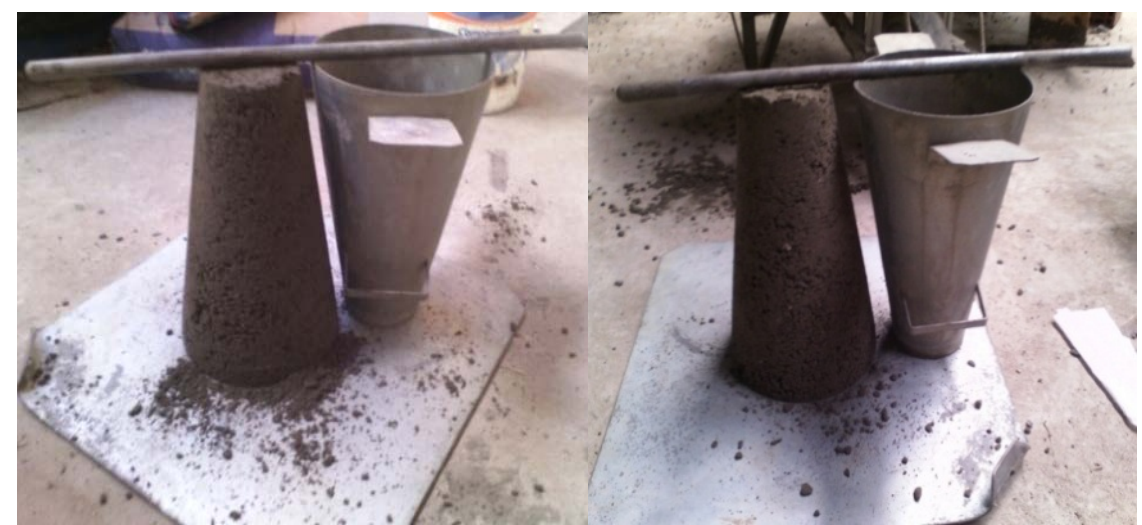

(a)

(b)

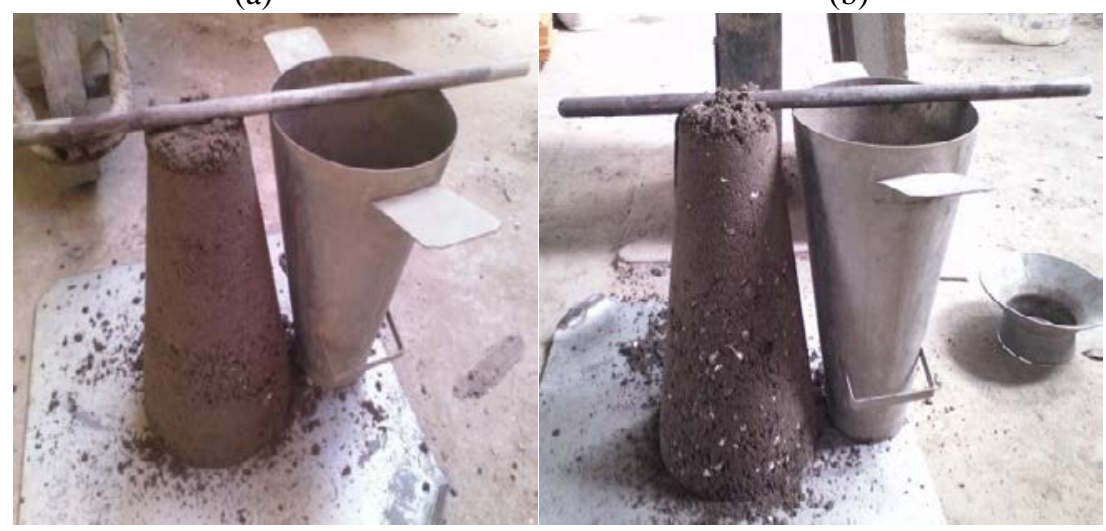

(c)

(d)

Para o ensaio de microscopia ótica, retiraram-se pequenas amostras com superfícies planas de cada tipo de bloco. Essas foram colocadas em moldes de PVC para embutimento a frio com resina líquida de poliéster, desmoldando-as após 24 horas. Posteriormente, para cada amostra, a parte inferior foi lixada e polida numa politriza velocidade média de $80 \mathrm{rpm}$, para que fossem observadas em um microscópio ótico, da marca Pantec, com controle manual dos deslocamentos do feixe de luz incidente sobre as amostras estudadas. As imagens foram capturadas pelo programa ScopeImage Advanced, acoplado ao microscópio.

\section{Análise das propriedades térmicas dos blocos}

Uma vez que as propriedades térmicas estão relacionadas à densidade, determinou-se essa característica dos blocos de acordo com a ASTM C140/C140M (AMERICAN..., 2014b).Sendo a análise dimensional outra variável necessária para este estudo, determinaram-seas dimensões dos blocos-testemunho segundo a NBR 12118 (ABNT, 2013a).
Considerando que a alvenaria de blocos de concreto se caracteriza como um sistema de vedações verticais internas e externas (SVVIE), esta deve obedecer aos requisitos da NBR 15575-4 (ABNT, 2013b), que limita a transmitância e a capacidade térmica em níveis de desempenho para a edificação. Sendo assim, obtiveram-se os valores dessas propriedades por meio dos procedimentos de cálculos descritos na NBR 15220-2 (ABNT, 2005a).

Além da determinação das propriedades normatizadas, complementou-se o estudo com a determinação do conforto térmico de ambientes formados por alvenarias compostas de dois tipos dos blocos (BREF e B15), baseando-se no experimento de Krüger et al. (2009). Para tanto, montaram-se duas caixas térmicas quepossuíam na parte superior um conjunto composto (de cima para baixo) detelhas de fibrocimento, folhas de compensado (com $4 \mathrm{~mm}$ de espessura) e placas de EPS (de $15 \mathrm{~mm}$ de espessura) com a função de isolamento térmico (Figura 5). A argamassa de assentamento dos blocos possuía traço de 1:6 (cimento:areia). 
Figura 5 - (a) Base de concreto, (b) paredes de alvenaria, (c) parte superior composta pelo conjunto compensado e EPS, empregados na fabricação da (d) caixa térmica

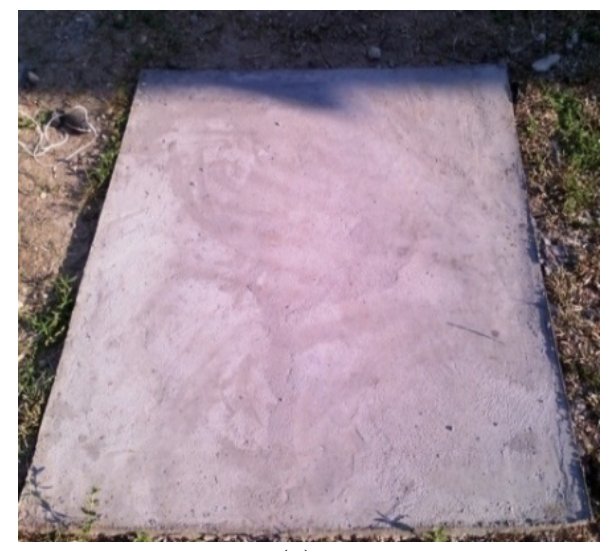

(a)

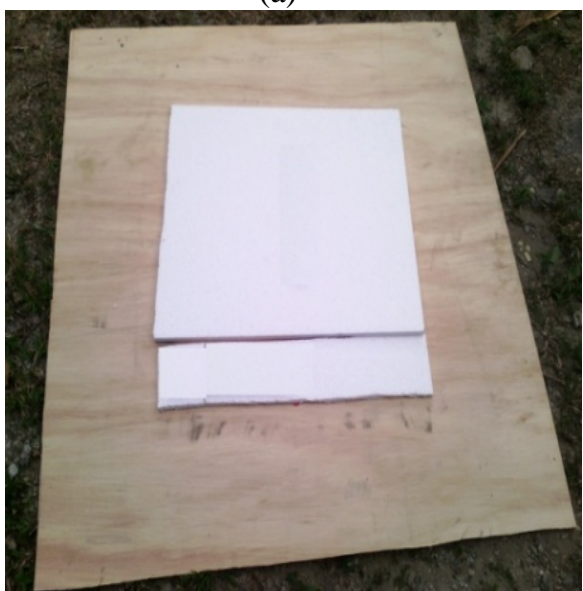

(c)

A escolha pelos blocos com $15 \%$ de substituição para esseexperimento ocorreu em função da afirmação Callister Júnior e Rethwisch (2016), de que o aumento volumétrico da porosidade de vazios sem circulação de ar (como os presentes nos grânulos de EPS) em materiais cerâmicos interfere sensivelmente na sua condutividade térmica, resultando em umatransferência de calor desprezível.

As variações térmicas das paredes internas e do ambiente foram medidas por um termômetro digital, com precisão de $1{ }^{\circ} \mathrm{C}$, instalado na parte superior das caixas, enquanto as variações externas da alvenaria foram obtidas com a utilização de uma câmera termográfica, da marca Flir, modelo T62101. A aquisição dos valores das temperaturas interna e externa ocorreu durante 6 horas (das 9h até as 15h) entre os dias 14 e 18 de agosto de 2017 (durante o período doverão amazônico).

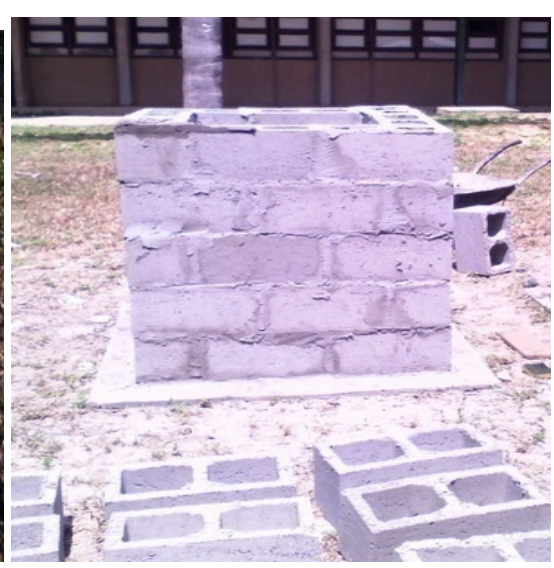

(b)

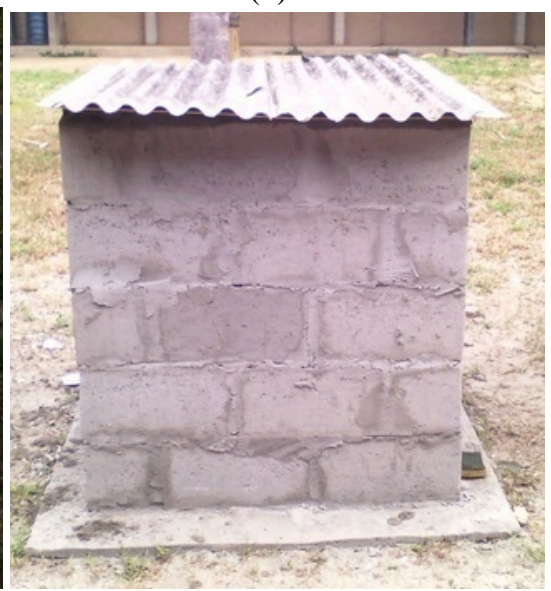

(d)

\section{Resultados e discussões}

\section{Resistência à compressão axial}

As resistências dos quatro tipos de blocos estão discriminadas na Tabela 2.

Pela classificação da NBR 6136 (ABNT, 2016), as amostras do tipo BREF pertencem à classe $\mathrm{C}$, com função estrutural para edificações com até cinco pavimentos, construídas acima do nível do solo, ou somente para vedação. Os blocos B5 pertencem à classe B, com função estrutural, enquanto os blocos B10 e B15 não atenderam a exigência da norma, invalidando o seu uso para qualquer tipo de alvenaria.

Verifica-se pela Tabela 3 que os resultados da Tabela 2 apresentaram valores abaixo dos apresentados nos estudos com blocos de concreto com EPS, considerando a incorporação do percentual volumétrico de 15\%. Contudo, ressaltase que nosestudos apresentados na Tabela 3 o consumo de cimento foi superior ao adotado na pesquisa. O baixo consumo de cimento dos blocos produzidos em relação aos dos estudos 
apresentados na Tabela 3 levou em consideração que o objetivo principal era obter blocos com resistência característica suficiente para que fossem enquadrados como blocos aptos para alvenaria conforme a NBR 6136 (ABNT, 2016), que impõe resistência característica a partir de $3 \mathrm{MPa}$ para vedação com ou sem função estrutural. Desse modo, não era objetivo da pesquisa obter blocos com resistênciassuperioresà estabelecida pela referida norma (8 $\mathrm{MPa})$.

Quanto aos tamanhos dos grânulos de EPS, os utilizados pelos autores citados na Tabela 3 e por Hernández-Zaragoza et al. (2013) possuíam granulometria uniforme e inferiores ao utilizado na pesquisa (diâmetro médio de $3 \mathrm{~mm}$, enquanto o da presente pesquisa é de aproximadamente $7 \mathrm{~mm}$ ), o que, segundo Liu e Chen (2014), favorecea obtenção de resistência mais elevada, devido ao efeito físico de preenchimento de vazios.

A substituição do poliestireno expandido ocorreu na pesquisa de $\mathrm{Xu}$ et al. (2012), em relação ao agregado miúdo, preservando a composição volumétrica do agregado graúdo usual, que notoriamente possuía a maior resistência à compressão na mistura.

O fator a/c adotado no trabalho de HernándezZaragoza et al. (2013) foi de 0,4, abaixo do escolhido para pesquisa, indicando possivelmente uma trabalhabilidade superiorà obtida nos blocos com EPS reciclado em função do emprego de um poliestireno mais liso e uniforme, ratificando o que Trussoni, Hays e Zollo (2012) e Demirboga e Kan (2012) haviam afirmado em seus respectivos estudos quando empregaram esse material no concreto em formato e textura distinta dos encontrados nas pérolas.

Além disso, Ling e Teo (2013) afirmam que a cura ao ar fornece resultados inferiores aos obtidos por amostras submetidas à cura úmida para uma mesma dosagem, visto que a resistência à compressão obtida em seu estudo para a cura ao ar foi inferior a $8 \mathrm{MPa}$ (Tabela 3), enquanto para a cura úmida o resultado foi superior a $12 \mathrm{MPa}$, o que se conclui que possivelmente com emprego da cura úmida os tipos B10 e B15 poderiam atingir resistências superiores àquelas apresentadas na Tabela 2.

Tabela 2 - Resistência à compressão axial dos blocos aos 28 dias

\begin{tabular}{|c|c|c|c|c|c|}
\hline Tipo & $\begin{array}{c}\text { Resistência da } \\
\text { amostra (MPa) }\end{array}$ & $\begin{array}{c}\text { Resistência } \\
\text { média (MPa) }\end{array}$ & $\begin{array}{c}\text { Resistência } \\
\text { característica (MPa) } \\
\end{array}$ & $\begin{array}{c}\begin{array}{c}\text { Desvio padrão } \\
\text { (MPa) }\end{array} \\
\end{array}$ & CV (\%) \\
\hline \multirow{4}{*}{ BREF } & 5,21 & \multirow{4}{*}{5,16} & \multirow{4}{*}{3,95} & \multirow{4}{*}{0,73} & \multirow{4}{*}{14,18} \\
\hline & 6,07 & & & & \\
\hline & 4,28 & & & & \\
\hline & 5,07 & & & & \\
\hline \multirow{4}{*}{ B5 } & 6,24 & \multirow{4}{*}{5,59} & \multirow{4}{*}{4,02} & \multirow{4}{*}{0,95} & \multirow{4}{*}{17,02} \\
\hline & 4,92 & & & & \\
\hline & 4,65 & & & & \\
\hline & 6,57 & & & & \\
\hline \multirow{4}{*}{ B10 } & 3,13 & \multirow{4}{*}{3,43} & \multirow{4}{*}{2,59} & \multirow{4}{*}{0,51} & \multirow{4}{*}{14,85} \\
\hline & 3,02 & & & & \\
\hline & 3,45 & & & & \\
\hline & 4,15 & & & & \\
\hline \multirow{4}{*}{ B15 } & 3,66 & \multirow{4}{*}{3,22} & \multirow{4}{*}{2,25} & \multirow{4}{*}{0,59} & \multirow{4}{*}{18,31} \\
\hline & 3,63 & & & & \\
\hline & 3,20 & & & & \\
\hline & 2,39 & & & & \\
\hline
\end{tabular}

Tabela 3 - Comparação entre a dosagem e a resistência adquirida dos blocos de concretos

\begin{tabular}{|c|c|c|c|}
\hline Autores & Tipo de cura & $\begin{array}{c}\text { Consumo de } \\
\text { cimento }\left(\mathrm{kg} / \mathrm{m}^{3}\right)\end{array}$ & $\begin{array}{c}\text { Resistência à } \\
\text { compressão (MPa) }\end{array}$ \\
\hline Xu et al. (2012) & Úmida & $\begin{array}{l}400 \\
450 \\
500 \\
\end{array}$ & $\begin{array}{l}20,77 \\
15,68 \\
18,56\end{array}$ \\
\hline $\begin{array}{c}\text { Ling e Teo } \\
\text { (2013) }\end{array}$ & Ao ar & 425 & 7,00 \\
\hline $\begin{array}{l}\text { Presente } \\
\text { pesquisa }\end{array}$ & Ao ar & 242 & 2,25 \\
\hline
\end{tabular}


Ao analisar o padrão dos dados mostrados na Tabela 2, verificou-seque houve uma distribuição platicúrtica dos valores encontrados, com maior

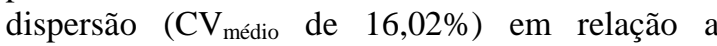
Hernández-Zaragoza et al. (2013), que apresentaram coeficiente de variação médioentre os seus dois tipos de blocos igual a 10,32\%. Ao comparar as tensões características, notou-se que a resistência à compressão característica praticamente não foi alterada com a substituição de 5\% do agregado graúdo pelo EPS reciclado em relação à BREF, concluindo-sepela ANOVA (Tabela 4a) que essa substituição não influiu nessa propriedade mecânica. Para os outros teores (B10 e B15) também não foi verificada essa influência, segundo a Tabela 4b.

Essa comparação vai ao encontro do estudo de Vieira et al. (2016), que definiu ser esseteor de substituição ideal para blocos de pavimentação. No entanto, a resistência característica encontrada na pesquisa apresentou valor muito inferior ao obtido pelos autores (15 $\mathrm{MPa}$ ), para moldagem dos corpos de prova cilíndricos do concreto com este tipo de EPS, conforme mostrado na Tabela 5, e esses autores adotaram um consumo de cimento superior ao adotado na pesquisa $\left(422 \mathrm{~kg} / \mathrm{m}^{3}\right)$. Os fatores que contribuíram para essadiferença são aqueles citados em função da comparação com os trabalhos de Xu et al. (2012), Hernández-Zaragoza et al. (2013) e Ling e Teo (2013), com exceção do fator a/c, que foi igual ao do estudo.
Ainda sobre a Tabela 2, observa-se quecom a substituição volumétrica a partir de $10 \%$ da brita pelo EPS reciclado foi verificadauma queda da resistência à compressão axial em função possivelmente da existência de zonas de má coesão (Figura 6) que contribuíram para o aumento de vazios nesses blocos. As reduções foram de 33,89\% e $40,44 \%$ para os blocos B10 e B15, respectivamente.

Com relação ao modo de ruptura dos blocos submetidos à compressão axial (Figura 6), notou-se um comportamento similar para todas as amostras analisadas, com o maior aparecimento de fissuras na direção paralela ao comprimento, o que, segundo Hernández-Zaragoza et al. (2013), estão relacionadas a tensões puramente de cisalhamento, enquanto as poucas fissuras inclinadas sugerem a presença de tensões localizadas. Comparando-se, por exemplo, com o trabalho de Xu et al. (2012), em que as fissuras ocorrem no sentido perpendicular ao identificado na pesquisa, percebese uma distinção no caminho preferencial das fissuras, pelo quese concluiu, pela análise visual, que existem zonas de má coesão situadas principalmente nas extremidades dos blocos, que favoreceriam essas ocorrências e que poderiam provavelmente ser corrigíveis, ao consultar as recomendações de Tango (1984), com ajustes, por exemplo, no tempo de vibrocompressão dos blocos.

Tabela 4 - Análise de variânciapara resistência à compressão dos tipos (a) BREF e B5 e (b) BREF, B10 e B15

\begin{tabular}{|c|c|c|c|c|c|}
\hline $\begin{array}{l}\text { Fonte de } \\
\text { variação }\end{array}$ & $\begin{array}{l}\text { Soma dos } \\
\text { quadrados }\end{array}$ & $\begin{array}{l}\text { Graus de } \\
\text { liberdade }\end{array}$ & $\begin{array}{c}\text { Média } \\
\text { quadrática }\end{array}$ & $\begin{array}{c}\text { Estatística de } \\
\text { Snedecor (Teste F) }\end{array}$ & $\begin{array}{c}\text { Significância } \\
\text { (p-valor) }\end{array}$ \\
\hline Teor de EPS & 0,38 & 1 & 0,38 & \multirow{3}{*}{0,51} & \multirow{3}{*}{0,50} \\
\hline Erro & 4,44 & 6 & \multirow{2}{*}{0,74} & & \\
\hline Total & 4,82 & 7 & & & \\
\hline \multicolumn{6}{|c|}{ (a) } \\
\hline $\begin{array}{l}\text { Fonte de } \\
\text { variação }\end{array}$ & $\begin{array}{l}\text { Soma dos } \\
\text { quadrados }\end{array}$ & $\begin{array}{l}\text { Graus de } \\
\text { liberdade }\end{array}$ & $\begin{array}{c}\text { Média } \\
\text { quadrática }\end{array}$ & $\begin{array}{c}\text { Estatística de } \\
\text { Snedecor (Teste F) }\end{array}$ & $\begin{array}{l}\text { Significância } \\
\text { (p-valor) }\end{array}$ \\
\hline Teor de EPS & 3,57 & 2 & 1,78 & \multirow{3}{*}{1,78} & \multirow{3}{*}{0,22} \\
\hline Erro & 9,04 & 9 & \multirow{2}{*}{1,00} & & \\
\hline Total & 12,61 & 11 & & & \\
\hline
\end{tabular}

(b)

Tabela 5 - Resistência à compressão axial dos corpos de prova cilíndricos

\begin{tabular}{c|c|c}
\hline Tipo & $\begin{array}{c}\text { Resistência } \\
\text { característica (MPa) }\end{array}$ & CV (\%) \\
\hline BREF & 5,17 & 3,74 \\
B5 & 3,94 & 14,24 \\
B10 & 4,04 & 6,24 \\
B15 & 3,86 & 6,63 \\
\hline
\end{tabular}


Figura 6 - Fissuração típica dos blocos submetidos à compressãoaxial
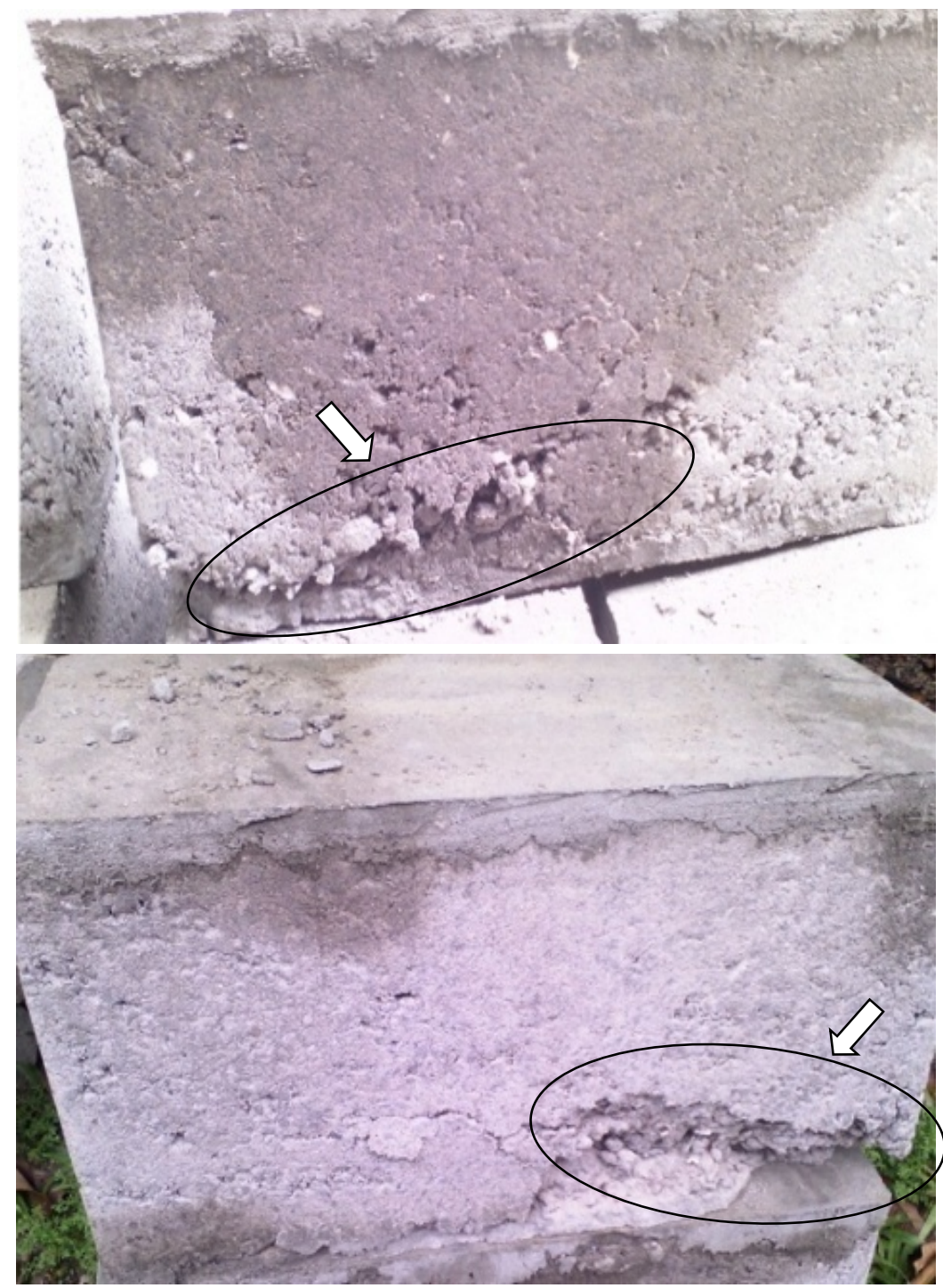

\section{Microscopia ótica}

Por meiodas imagens das amostras dos blocos, percebeu-se que em BREF (Figura 7a) e B5 (Figura 7b) foram encontrados vazios aparentes apenas nos agregados graúdos (setas brancas)e nos grãos visíveis de areia (setas verdes), intrínsecos aos próprios agregados. Contudo, nas amostras B10 (Figura 7c) e B15 foi possível encontrar também alguns vazios (setas azuis) na matriz cimentícia, indicando uma quantidade superior nesses blocos em relação ao BREF e B5, além do aspecto menos uniforme da argamassa (Figura 7d), podendo estar relacionado à incorporação de ar enclausurado que os agregados leves como o EPS reciclado tendem a introduzir nos concretos aos quais são adicionados, conforme afirma Hernández-Zaragoza et al. (2013). Esses vazios na matriz podem ter contribuído em parte paraa queda na resistência à compressão apresentada pelos blocos B10 e B15 em relação ao BREF e B5.

Em relação à zona de transição (seta vermelha)entre a matriz cimentícia (seta amarela) e o agregado graúdo (seta branca), percebeu-se que em todas as imagens não foram encontrados vaziosnessa região, o que indicapossivelmente que a argamassa foi suficiente para realizar a ligação com o agregado graúdo, conforme exemplificado na Figura 8. Contudo, não se descarta totalmente aausência de vazios na zona de transição matriz-agregado devido à quantidade de cimento ser inferior à comumente empregada (acima de $300 \mathrm{~kg} / \mathrm{m}^{3}$ ).

\section{Umidade relativa e absorção}

Os teores de umidade e absorção dos blocostestemunhoestão expressos na Tabela 6. 
Quanto às recomendações para esses índices físicos, identificou-seque todos os blocos atenderam as exigências da NBR 12118 (ABNT, 2013a), que determina, para resistências inferiores a $8 \mathrm{MPa}$, uma variação percentual de $10 \%$ a $40 \%$ para a umidade relativa. Para absorção, o valor máximo permitido é de 9\%, segundo a NBR 6136 (ABNT, 2016), o que também foi alcançado por todos os tipos de blocos produzidos. Ao se comparar os resultados obtidos com os de Hernández-Zaragoza et al. (2013), constatou-se que as variações foram similares para os dois tipos de blocos produzidos pelos autores, os quais possuíam um percentual de absorção de 9,3\% para concretos com quantidade de 600 gramas de pérolas de EPS.

O teor de EPS reciclado apresentourelação inversa para umidade relativa em função do aumento da água livre presente na mistura, que evaporou com maior facilidade devido à hidrofobia do poliestireno expandido. Quanto à absorção, identificou-se uma relação direta, o que permitiuque os blocos incorporassem maiores quantidades de fluidos, apresentando comportamento esperado ao comparar-se com o trabalho de HernándezZaragoza et al. (2013).

Destaca-se, contudo, que as análises dessas propriedades físicas não levaram em consideração que os blocos B10 e B15 possuíam resistências abaixo da mínima imposta pela NBR 6136 (ABNT, 2016).

\section{Análise dimensional e densidade}

Os valores médios das dimensões dos blocos obtidos segundo a NBR 12118 (ABNT, 2013a) são mostrados na Tabela 7.

\section{Figura 7 - Imagens das matrizes cimentícias dos blocos (a) BREF, (b) B5 e (c) B10 e (d) B15 com} ampliação de $400 x$

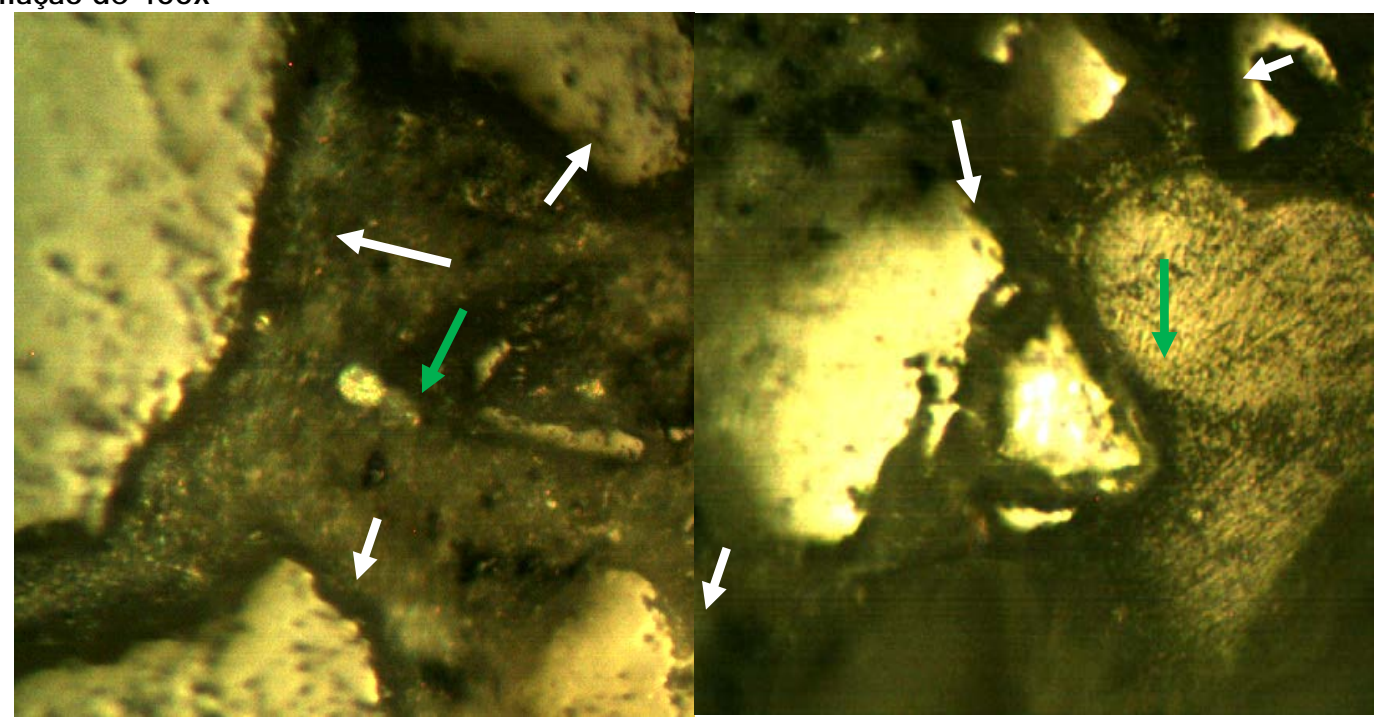

(a)

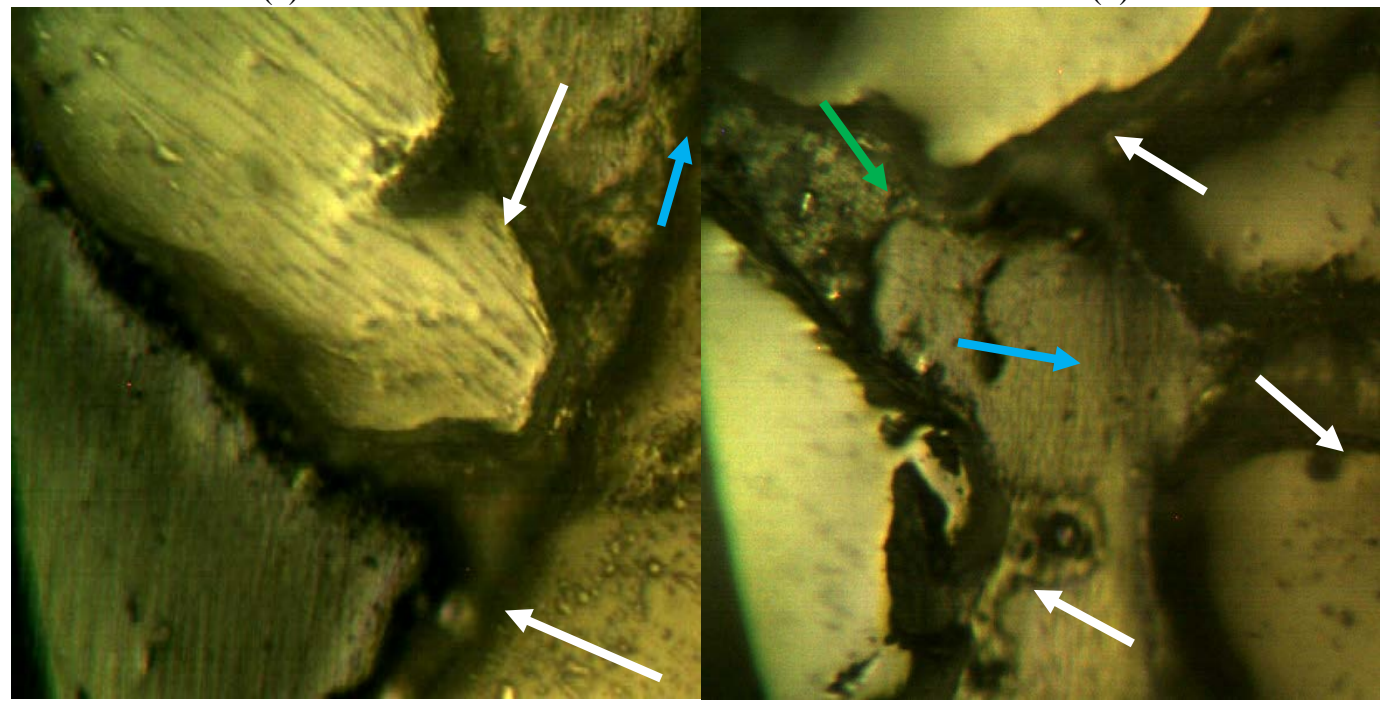

(c) (d) 
Figura 8 - Zona de transição matriz-agregado encontrada em B15

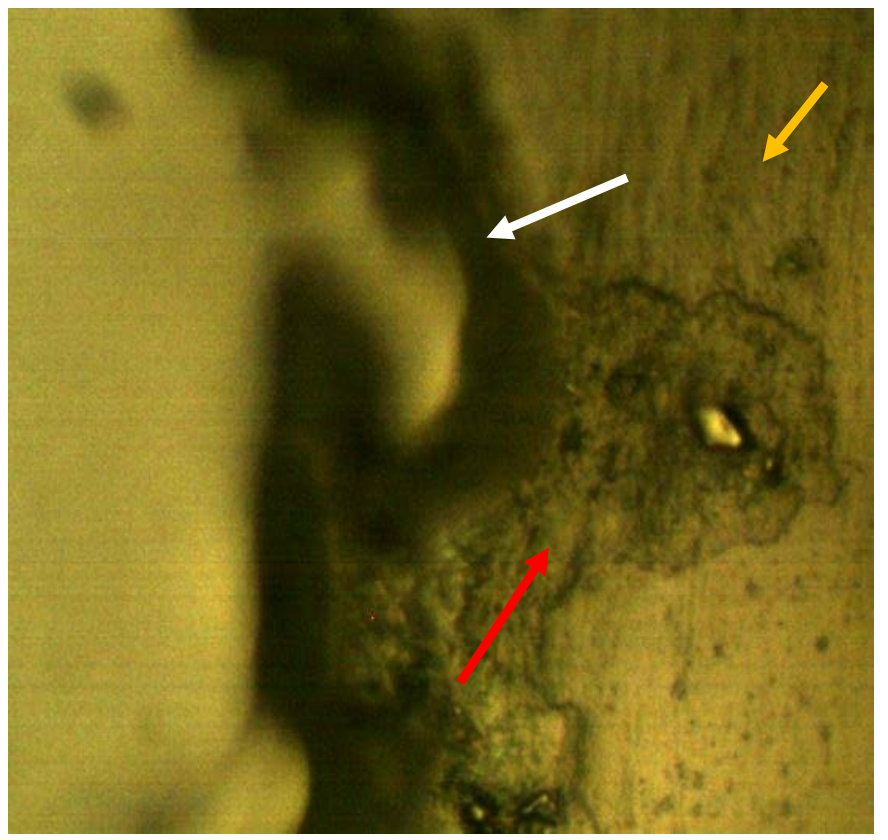

Tabela 6 - Umidade relativa e absorção dos blocos

\begin{tabular}{c|c|c|c|c}
\hline Tipo & $\begin{array}{c}\text { Umidade } \\
\text { relativa (\%) }\end{array}$ & CV (\%) & Absorção (\%) & CV (\%) \\
\hline BREF & 30,49 & 3,41 & 5,91 & 4,95 \\
B5 & 27,88 & 12,07 & 6,33 & 10,96 \\
B10 & 26,56 & 8,81 & 7,07 & 2,82 \\
B15 & 25,24 & 3,98 & 8,69 & 4,40 \\
\hline
\end{tabular}

Tabela 7 - Dimensões reais dos blocos-testemunho

\begin{tabular}{c|c|c|c|c|c|c}
\hline \multirow{2}{*}{ Tipo } & \multirow{2}{*}{$\begin{array}{c}\text { Parede } \\
\text { longitudin } \\
\text { al (mm) }\end{array}$} & $\begin{array}{c}\text { Paredes } \\
\text { (mm) }\end{array}$ & $\begin{array}{c}\text { Espessura } \\
\text { equivalente } \mathbf{( m m} / \mathbf{m})\end{array}$ & $\begin{array}{c}\text { Comprimento } \\
\mathbf{( m m})\end{array}$ & $\begin{array}{c}\text { Largura } \\
\mathbf{( m m})\end{array}$ & $\begin{array}{c}\text { Altura } \\
(\mathbf{m m})\end{array}$ \\
\hline BREF & $31,6 \pm 0,4$ & $32,0 \pm 0,5$ & 246,2 & $390,3 \pm 0,2$ & $190,9 \pm 1,5$ & $202,3 \pm 0,7$ \\
B5 & $31,3 \pm 0,2$ & $31,3 \pm 0,6$ & 240,8 & $389,6 \pm 0,1$ & $190,0 \pm 0,1$ & $200,8 \pm 0,2$ \\
B10 & $31,0 \pm 0,1$ & $31,2 \pm 0,6$ & 240,0 & $389,7 \pm 0,0$ & $190,5 \pm 0,6$ & $198,4 \pm 1,7$ \\
B15 & $31,1 \pm 0,4$ & $31,1 \pm 0,4$ & 239,5 & $389,6 \pm 0,3$ & $191,0 \pm 0,9$ & $199,2 \pm 2,7$ \\
\hline
\end{tabular}

Ao comparar os resultados dos blocos apresentados na Tabela 6, verificou-se reduções das dimensões das paredes transversais e das espessuras equivalentes (que consiste na razão entre o somatório das paredes transversais pelo comprimento) com a presença do EPS na mistura. Como neste estudo não houve preocupação com a classe dos blocos, os requisitos impostos pela NBR 6136 (ABNT, 2016) para essas dimensões não foram levados em consideração. Quanto à altura, comprimento e largura, não há imposições que invalidem os resultados obtidos. As variações dimensionais encontradas entre as amostras, apesar da utilização da mesma fôrma, estão provavelmente relacionadas a possíveis falhasno processo produtivo, segundo as definições de Tango (1984) Todavia, essas variações dimensionais não foram significativas e não influenciaram nos valores das massas específicas para os blocos produzidos na pesquisa, as quais estão expressas na Tabela 8.

Identificou-se, conforme os limites estabelecidos pela ASTM C55 (AMERICAN..., 2014a), que nenhuma das amostras foi classificada como bloco de concreto leve, designando-se ostipos B5, B10 e B15 como blocos de concreto de peso médio, enquanto o tipo BREF se situava próximo ao limite inferior dos blocos normais.Os teores de EPS na mistura seca não interferiram sensivelmente nos pesos dos blocos, situando-se numa faixa de valores semelhantes aos obtidos por Xu et al. (2012) e Ling 
e Theo (2013), mas inferior aos de HernándezZaragoza et al. (2013), que utilizaram outras dosagens.

\section{Desempenho térmico}

Com relação às propriedades térmicas, os valores obtidos pelos procedimentos de cálculos descritos na NBR 15220-2 (ABNT, 2005a) estão apresentados na Tabela 9 .

Para análise dos resultados, inicialmente identificou-se que a região amazônica, segundo NBR 15220-3 (ABNT, 2005b), pertence à zona 8. De posse dessa informação, verificou-se que não haveria requisito para capacidade térmica, de acordo com a NBR 15575-4 (ABNT, 2013b), o que possibilitaria o uso dos blocos para alvenaria externa e interna. Os valores encontrados, no entanto, foram superiores à capacidade de $115 \mathrm{~kJ} / \mathrm{m}^{2} . \mathrm{K}$ obtida por Pedra (2011), que estudou blocos vazados de concreto com preenchimento de seus vazios aparentes por pérolas de EPS com $2 \mathrm{~mm}$ de diâmetro.
Em relação à transmitância térmica, constatou-se o mesmo resultado independentemente do acréscimo de EPS, e o valor de $2,79 \mathrm{~W} / \mathrm{m}^{2} . \mathrm{K}$ é superior ao limite máximo estabelecido de $2,5 \mathrm{~W} / \mathrm{m}^{2} . \mathrm{K}$ pela NBR 15575-4 (ABNT, 2013b). Porém, essevalor é inferior àquele de $3,12 \mathrm{~W} / \mathrm{m}^{2} . \mathrm{K}$ encontrado por Pedra (2011). Os principais responsáveis pela manutenção da transmitância térmica dos blocos da pesquisa estão relacionados às suas dimensões $e$ geometria, alémda baixa redução do peso específico com a incorporação do EPS reciclado.

\section{Conforto térmico}

As medidas das temperaturas, cujos valores médios sãoreferentes aos cinco dias do experimento, estão apresentadas na Tabela 10.

Percebe-se, pelos valores da Tabela 9, que as temperaturas internas das caixas apresentaram o mesmo valor ao meio-dia e foram semelhantes nos outros horários, com diferença máxima de $0,6{ }^{\circ} \mathrm{C}$ às 15h, diferença essa inferior à precisão dotermômetro utilizado, sendo considerada desprezível.

Tabela 8 - Massas específicas secas dos blocos

\begin{tabular}{c|c|c|c}
\hline Tipo & $\begin{array}{c}\text { Massa específica } \\
\text { seca }\left(\mathbf{k g} / \mathbf{m}^{3}\right)\end{array}$ & $\mathbf{C V} \mathbf{( \% )}$ & $\begin{array}{c}\text { Reduçãoem relação } \\
\text { ao referencial (\%) }\end{array}$ \\
\hline BREF & 2035,66 & 0,27 & - \\
B5 & 1956,47 & 0,65 & 3,89 \\
B10 & 1910,79 & 0,19 & 6,13 \\
B15 & 1878,68 & 0,35 & 7,71 \\
\hline
\end{tabular}

Tabela 9 - Propriedades térmicas dos blocos moldados

\begin{tabular}{|c|c|c|}
\hline Tipo & $\begin{array}{c}\text { Transmitância térmica } \\
\text { “U” }\left(W / \mathbf{m}^{2} . K\right)\end{array}$ & $\begin{array}{c}\text { Capacidade térmica “C” } \\
\left(\mathrm{kJ} / \mathrm{m}^{2} . \mathrm{K}\right)\end{array}$ \\
\hline BREF & 2,79 & 154,14 \\
\hline B5 & 2,79 & 146,08 \\
\hline B10 & 2,79 & 141,63 \\
\hline B15 & 2,79 & 139,34 \\
\hline
\end{tabular}

Tabela 10 - Temperaturas médias das caixas de alvenaria e do ambiente

\begin{tabular}{|c|c|c|c|c|c|}
\hline \multirow{2}{*}{ Horário (h) } & \multicolumn{2}{|c|}{ BREF } & \multicolumn{2}{|c|}{ B15 } & \multirow{2}{*}{$\begin{array}{l}\text { Temperatura } \\
\text { ambiente }\left({ }^{\circ} \mathrm{C}\right)\end{array}$} \\
\hline & $\mathrm{T}_{\text {interna }}\left({ }^{\circ} \mathrm{C}\right)$ & $\mathrm{T}_{\text {externa }}\left({ }^{\circ} \mathrm{C}\right)$ & $T_{\text {interna }}\left({ }^{\circ} \mathrm{C}\right)$ & $T_{\text {externa }}\left({ }^{\circ} \mathrm{C}\right)$ & \\
\hline 9:00 & $30,6 \pm 0,5$ & $32,8 \pm 1,2$ & $30,7 \pm 0,5$ & $34,2 \pm 0,9$ & $35,6 \pm 2,6$ \\
\hline $10: 00$ & $31,7 \pm 0,8$ & $38,3 \pm 1,0$ & $32,1 \pm 1,5$ & $37,9 \pm 0,8$ & $36,5 \pm 1,2$ \\
\hline $11: 00$ & $32,7 \pm 0,4$ & $40,9 \pm 0,6$ & $32,9 \pm 0,3$ & $40,5 \pm 0,3$ & $37,9 \pm 1,9$ \\
\hline $12: 00$ & $34,5 \pm 0,6$ & $42,5 \pm 1,3$ & $34,5 \pm 1,1$ & $43,1 \pm 0,8$ & $38,6 \pm 0,6$ \\
\hline $13: 00$ & $36,2 \pm 0,6$ & $43,3 \pm 1,2$ & $36,6 \pm 1,2$ & $45,0 \pm 1,0$ & $39,4 \pm 1,9$ \\
\hline $14: 00$ & $37,4 \pm 1,0$ & $42,7 \pm 2,3$ & $37,6 \pm 1,1$ & $46,1 \pm 3,1$ & $38,8 \pm 2,1$ \\
\hline $15: 00$ & $37,7 \pm 0,5$ & $41,9 \pm 1,7$ & $38,3 \pm 0,7$ & $44,9 \pm 2,8$ & $38,7 \pm 0,8$ \\
\hline
\end{tabular}


A semelhança das temperaturas internas pode estar associada ao fato dos materiais apresentaremà mesma transmitância térmica. Ofenômeno de convecção ocorrido nas câmaras de ar também favorece maior transferência térmica devido à umidade presente, visto que Krüger et al. (2009) sugeriram a aplicação de placas do seu compósito sem a presença de vazios entre elas para evitar esse efeito. Callister Júnior e Rethwisch (2016) afirmam ainda que existe uma relação proporcional entre transferência por radiação e condutividade térmica, facilitando a transmissão de calor e anulando a diferença da capacidade térmica encontrada nos dois tipos de blocos.

As diferenças das temperaturas internas em relação à temperatura do ar mostram a eficiência do emprego dos blocos pararestrição da passagem de calor ao ambiente interno, comdecréscimos de 5,2 ${ }^{\circ} \mathrm{C}$ e $5{ }^{\circ} \mathrm{C}$, às $11 \mathrm{~h}$, para as alvenarias compostas dosblocos BREF e B15, respectivamente. Para Krüger et al. (2009) as diferenças nas temperaturas máximas entre os ambientes externos e internos no horário de pico de verão foram de $+0,3{ }^{\circ} \mathrm{C}$ para a alvenaria formada pelo compósito produzido pelos autores e $-1,5{ }^{\circ} \mathrm{C}$ para a alvenaria de tijolos cerâmicos. O comportamento das variações térmicas internas nos dois tipos de blocos ao longo do dia, com aumento de suas temperaturas até o último horário (acréscimos médios por hora de 1,2 ${ }^{\circ} \mathrm{C}$ e $1,3{ }^{\circ} \mathrm{C}$ para BREF e B15, respectivamente), mesmo com redução da temperatura ambiente a partir das 13h, demonstram atraso térmico para ambas as alvenarias.

Notou-se que, apesar das variáveis externas presentes no experimento devido a sua execução em local aberto, a interferência do sombreamento nas faces pertencentes a cada uma das caixas sob mesma orientação pouco interferiu na diferença de $1,4{ }^{\circ} \mathrm{C}$ encontrada às $9 \mathrm{~h}$, conforme exemplificado na Figura 9. O mesmo argumento aplica-se nas alterações do ângulo de incidência do sol ao longo do dia, pois foi percebido que às $15 \mathrm{~h}$ a diminuição da temperatura média do tipo B15 (mais ao leste) foi sensivelmente superior àdo BREF, com redução horária de $1,2{ }^{\circ} \mathrm{C}$ e $0,8{ }^{\circ} \mathrm{C}$, respectivamente.

Contudo, ao se comparar faces de paredes compostas de áreas sombreadas (em função da cobertura) a outras expostas diretamente ao sol, encontraram-se diferenças pontuais de $4{ }^{\circ} \mathrm{C}$ e médias superficiais de $5,5^{\circ} \mathrm{C}$ a $7,5^{\circ} \mathrm{C}$ entre as partes superior e inferior (sendo as maiores frequentemente encontradas no tipo B15), que serviram como justificativa para as diferentes absorções de calor encontrada nas duas alvenarias, conforme demonstrado na Figura 10.
A interpretação dos valores médios de calor presentes no lado externo das paredesmostrou a maior emissão de energia dos blocos B15 em relação ao BREF nos horários mais quentes, com temperatura (às $14 \mathrm{~h}$ ) $7,3{ }^{\circ} \mathrm{C}$ e $3,4^{\circ} \mathrm{C}$ acima das encontradas no ambiente e na alvenaria referencial, respectivamente, apresentando comportamento semelhante ao obtido por Ribeiro (2016), que estudou o desempenho térmico de placas cimentícias com e sem a presença de resíduos madeireiros.

Essa dificuldade na transmissão interna de calor é típica de materiais que apresentam maior isolação térmica, comprovando que a mudança ocasionada pela incorporação do EPS na mistura do concreto não alterou drasticamente sua característica térmica. Pedra (2011) observou comportamento semelhante ao identificar maiores temperaturas na superfície oposta ao fluxo de calor em blocos sem EPS em comparação aos que apresentavam esse polímero.

O gráfico das variações entre os ambientes internos e externos da caixa ao longo do tempo (Figura 11) mostrou que a diferença encontrada para o tipo B15 foi $27,57 \%$ superior ao encontrado para BREF às 14h. Comparando-se esses percentuais com os resultados de Ribeiro (2016), que utilizou fontes artificiais de calor nos interiores das caixas térmicas, verificou-se que os blocos apresentaram menor variação térmica entre os ambientes internos e externos em relação aos painéis cimentícios com os resíduos de madeira.

Do gráfico da Figura 11 percebe-se ainda comportamentos distintos para os dois tipos de blocos, pois próximo das $11 \mathrm{~h}$ obtiveram-se as maiores diferenças de temperatura entre os lados externos e internos das paredes para $\operatorname{BREF}\left(7,2^{\circ} \mathrm{C}\right.$ contra $3,1^{\circ} \mathrm{C}$ das paredes de B15), enquanto que após essehorário as diferenças sofreram uma queda, apesar da oscilação entre às $12 \mathrm{~h}$ e $13 \mathrm{~h}$. Para os blocos B15, houve uma contínua elevação até aproximadamente às $13 \mathrm{~h}$, com acentuado declive que o equiparou a outra curva às $15 \mathrm{~h}\left(6{ }^{\circ} \mathrm{C}\right.$ a $5,9{ }^{\circ} \mathrm{C}$ para as paredes com BREF).

Com isso, concluiu-se que as paredes de alvenaria dos blocos B15 mostraram maior inércia térmica nos horários de maior temperatura, emboraa temperatura interna tenha sido praticamente a mesma obtida na caixa com BREF. Apesar das altas temperaturas externas de B15, levou-se mais tempo para transmissão de calor em comparação ao BREF, ou seja, apresentou atraso térmico maior durante esse mesmo período. 
Figura 9 - Termogramas da face da parede sombreada dos blocos BREF (a) e da correspondente para os blocos B15 (b) sob total ação do sol

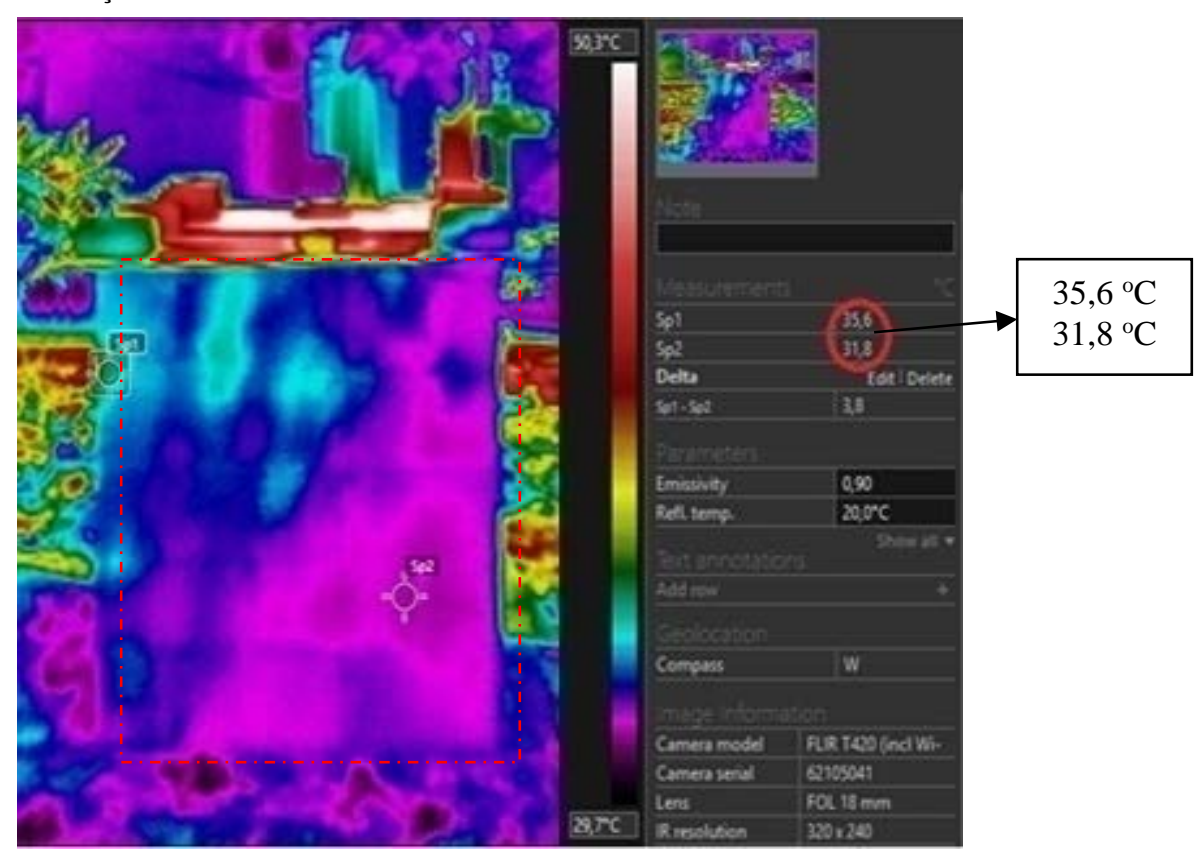

(a)

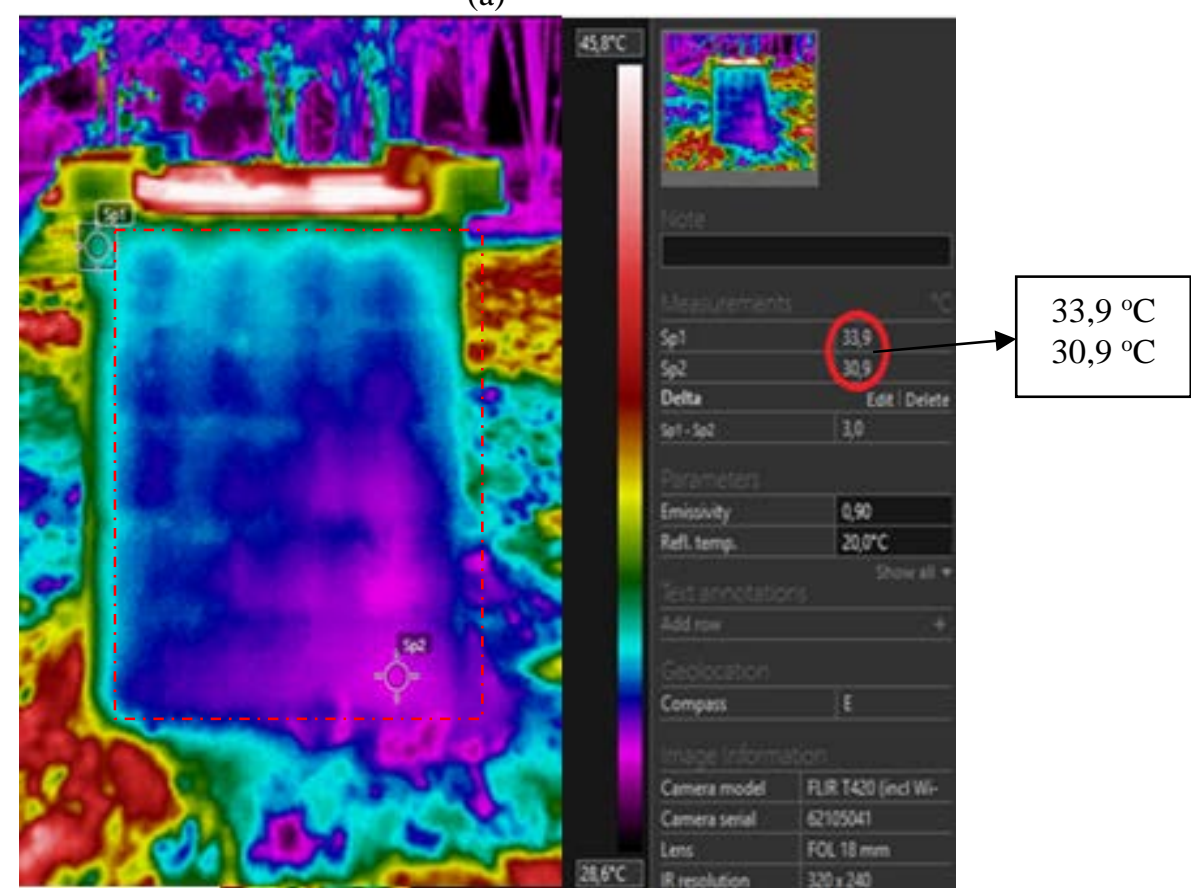

(b) 
Figura 10 - Termogramas das paredes, sob mesmo direcionamento, dos blocos B15 (a) e BREF (b) com sombreamento da cobertura

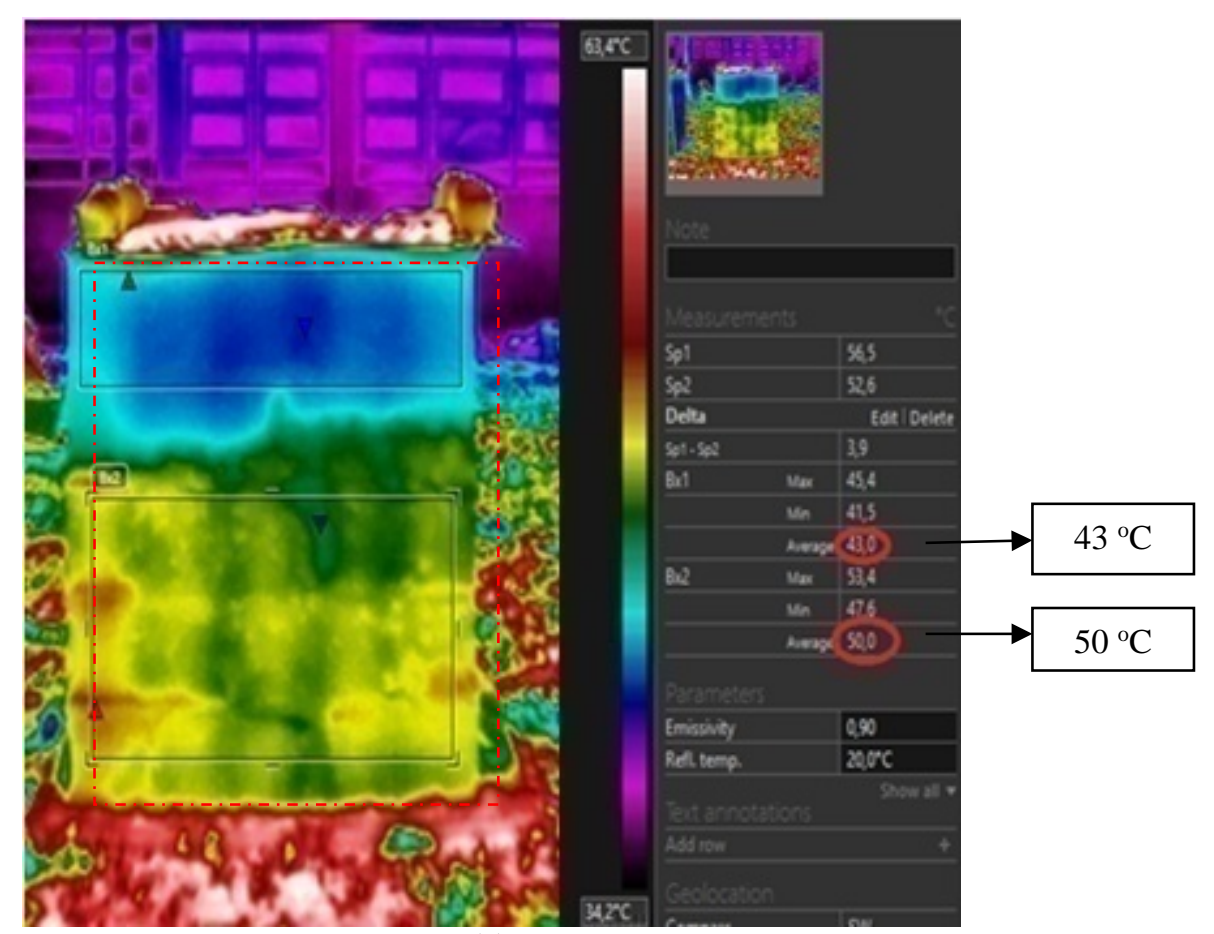

(a)

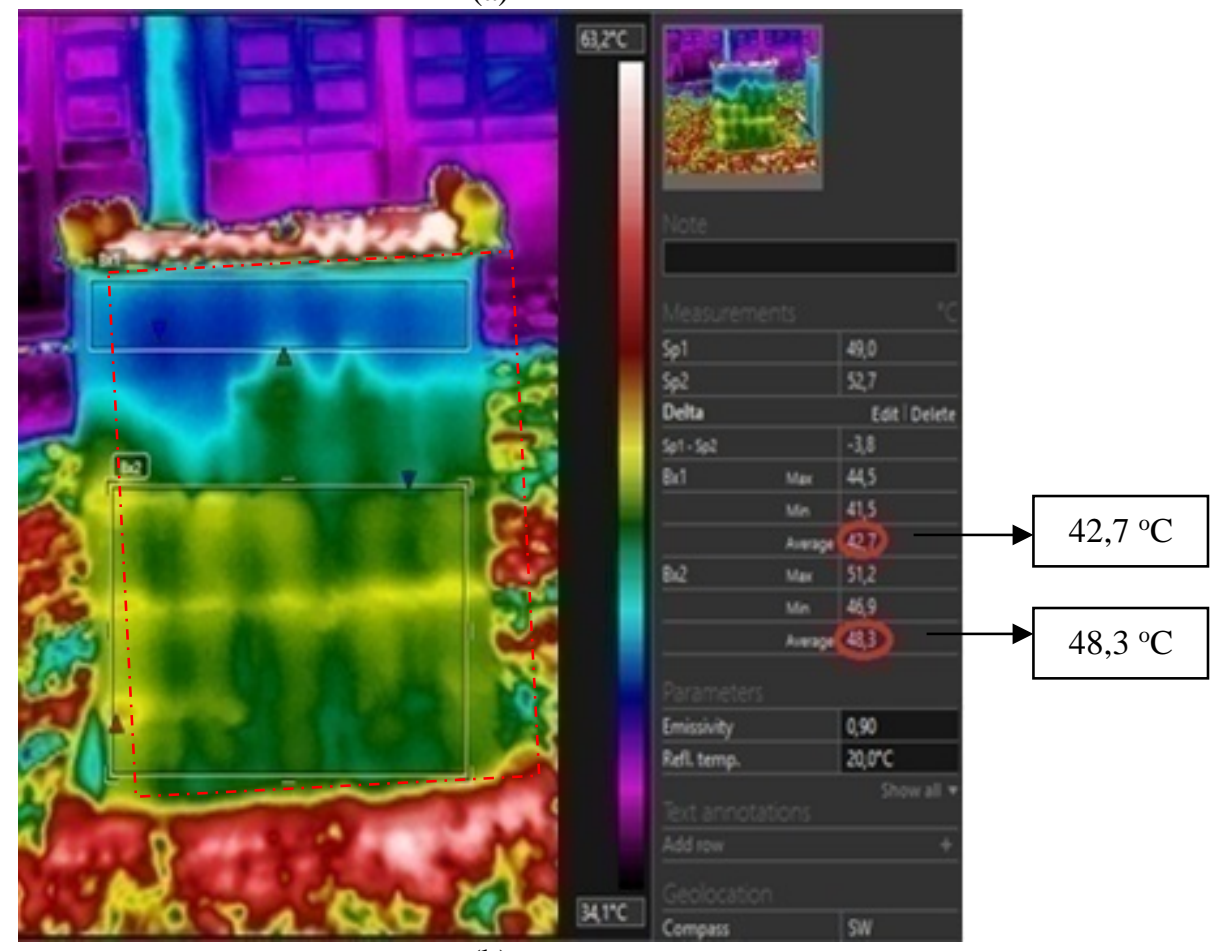

(b) 
Figura 11 - Gráfico das variações entre os ambientes da caixa x horário de medição

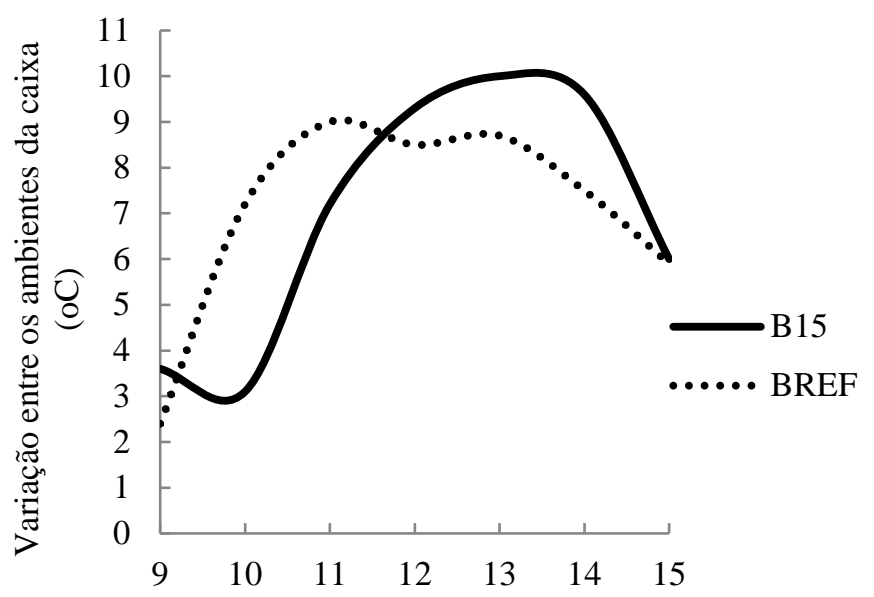

Horário de aferição (h)

Logo, pode-se admitir que possivelmente esses resultados surgiram em função da pequena redução da densidade dos blocos e do aumento devazios enclausurados de ar seco, responsáveis por atrasar a propagação de calor de uma extremidade a outra da parede, de acordo com Callister Júnior e Rethwisch (2016).

Ao se comparar os resultados oriundos das relações entre as diferenças das temperaturas máximas e mínimas internas e externas das duas alvenarias $\left(\Delta_{\text {int }} / \Delta_{\text {ext }}\right)$ com os descritos por Krüger et al. (2009), constatou-se que os valores apresentaram fatores de acréscimo iguais a 1,8 para BREF e 2,0 para B15, enquanto para o estudo referencial, que empregou placas cimentícias com resíduos de madeira, foram encontrados fatores de decréscimos de 0,84 e 0,97 para as estações de inverno e verão, respectivamente,quando foi realizado o experimento (em ambiente aberto). Isso, de acordo com os mesmos autores, reflete a necessidade de ajustes nos processos construtivos e arquitetônicos para diminuir a sensibilidade perante as variações da temperaturaambiente.

\section{Conclusões}

Da análise dos resultados apresentados neste trabalho, é possível chegaràs seguintes conclusões:

(a) o MEC mostrou-se eficiente para definição da relação cimento-agregado, enquanto a razão entre os agregados obtida pela metodologia experimental de Tango apresentou-se mais adequada na determinação da dosagem final dos componentes do concreto, conduzindo a dosagem experimental proposta neste artigo;

(b) os limites estabelecidos pela NBR 6136 (ABNT, 2016) para resistência à compressão axial dos blocos foram atendidos apenas para os tipos BREF e B5, visto que as amostras B10 e B15 não alcançaram a resistência mínimade vedação;

(c) a resistência mecânica possui relação inversa ao teor de EPS incorporado a mistura a partir de $10 \%$ da substituição do agregado graúdo, com redução da resistência à compressão média de aproximadamente $40 \%$ para o tipo B15 em relação ao valor referencial (sem a presença do polímero reciclado na mistura). As principais causas dessa queda estão relacionadas ao tamanho dos grânulos de EPS, ao baixo consumo de cimento eao processo produtivo empregado. A microscopia ótica sugere que as maiores heterogeneidades e os vazios presentes nas matrizes de B10 e B15 também possam ter contribuído para as resistências determinadas;

(d) os teores de absorção dos quatro tipos deblocos apresentaram relação inversa ao percentual volumétrico de EPS reciclado presente no concreto, com valores abaixo do limite mínimo imposto pela NBR 6136 (ABNT, 2016), oriundopossivelmente do aumento dos vazios no bloco, visto que o EPS reciclado pode ser considerado como um tipo de vazio induzido artificialmente;

(e) as umidades relativas de todos os blocostestemunho estiveram dentro da faixa de variação imposta pela NBR 12118 (ABNT, 2013a). Em comparação ao teor de EPSreciclado adotado, estabeleceu-se uma razão diretamente proporcional com essa propriedade física;

(f) o teor de $5 \%$ foi definido como o limite para substituição parcial do agregado graúdo natural por EPS reciclado para produção de blocos vazados de concreto, sem perda das características físicas e mecânicas em relação aos blocos referenciais, 
podendo ser utilizado para fins estruturais com a dosagem e a tecnologia adotadas na pesquisa;

(g) a redução da densidade dos blocos em função do aumento do teor de EPS resultou em um decréscimo teórico da capacidade térmica de 9,6\% para o tipo B15, comprovado pelo experimento prático, visto que a caixa produzida com esse tipo de bloco apresentou diferença entre as paredes internas e externas $27,6 \%$ superior à proporcionada pela alvenaria composta dos blocos do tipo BREF, ocasionando maior inércia e atraso térmico no horário de pico do experimento;

(h) as paredes construídas com os blocos B15 apresentaram transmissão de calor inferior à encontrada nas paredes compostas dosblocos BREF nos horários de temperaturas mais elevadas, resultando em um fator de acréscimo superior para os blocos B15, expondo a necessidade de ajustes na produção dos blocos para melhoria da eficiência térmica;

(i) nenhumdos blocos poderia ser empregado em alvenaria externa aparente, pois apresentaram transmitância térmica acima do máximo permitido pela NBR 15575-4 (ABNT, 2013b); e

(j) a incorporação de 15\% do EPS reciclado em substituição ao agregado graúdo convencionalgerouuma temperatura interna (no mesmo horário) semelhante à proporcionada pelos blocos referenciais,oriundo provavelmente dastransmitâncias térmicas iguais dos tipos BREF e B15 e das distintas temperaturas radiantes que anularam as diferenças encontradas nas capacidades térmicas desses blocos.

\section{Referências}

ALMEIDA, M. O.; SOUSA, J. G. G.; LIMA, L. C. Estudo de Dosagem para Produção de Blocos de Concreto. In: CONGRESSO BRASILEIRO DE ENGENHARIA E CIÊNCIA DOS MATERIAIS, 20., Joinville, 2012. Anais... Joinvile, 2012.

\section{AMERICAN CONCRETE INSTITUTE. ACI}

211.2: standard practice for selecting proportions for structural lightweight concrete. Michigan, 1998.

\section{AMERICAN SOCIETY FOR TESTING AND MATERIALS INTERNATIONAL.}

C140M/C140: standard specification for sampling and testing concrete masonry units and related units. West Conshohocken, 2014b.

AMERICAN SOCIETY FOR TESTING AND MATERIALS INTERNATIONAL. C55: standard specification for concrete building brick.West Conshohocken, 2014a.
ASSOCIAÇÃO BRASILEIRA DE NORMAS TÉCNICAS. NBR 12118: blocos vazados de concreto simples para alvenaria: métodos de ensaio. Rio de Janeiro, 2013a.

ASSOCIAÇÃO BRASILEIRA DE NORMAS TÉCNICAS. NBR 15220-2: desempenho térmico de edificações: parte 2: métodos de cálculo da transmitância térmica, da capacidade térmica, do atraso térmico e do fator solar de elementos e componentes de edificações. Rio de Janeiro, 2005a.

\section{ASSOCIAÇÃO BRASILEIRA DE NORMAS}

TÉCNICAS. NBR 15220-3: desempenho térmico de edificações: parte 3: zoneamento bioclimático brasileiro e diretrizes construtivas para habitações unifamiliares de interesse social. Rio de Janeiro, 2005b.

\section{ASSOCIAÇÃO BRASILEIRA DE NORMAS TÉCNICAS. NBR 15575-4: edificações} habitacionais: desempenho: parte 4: sistemas de vedações verticais internas e externas. Rio de Janeiro, 2013b.

ASSOCIAÇÃO BRASILEIRA DE NORMAS TÉCNICAS. NBR 5738: procedimento para moldagem e cura de corpos de prova. Rio de Janeiro, 2015.

ASSOCIAÇÃO BRASILEIRA DE NORMAS TÉCNICAS. NBR 5739: concreto: ensaio de compressão de corpos de prova cilíndricos. Rio de Janeiro, 2007.

\section{ASSOCIAÇÃO BRASILEIRA DE NORMAS \\ TÉCNICAS. NBR 6136: blocos vazados de} concreto para alvenaria simples: requisitos. Rio de Janeiro, 2016.

\section{ASSOCIAÇÃO BRASILEIRA DE NORMAS TÉCNICAS. NBR NM 23: cimento Portland e outros materiais em pó: determinação da massa específica. Rio de Janeiro, 2001.}

\section{ASSOCIAÇÃO BRASILEIRA DE NORMAS TÉCNICAS. NBR NM 248: agregados:} determinação da composição granulométrica. Rio de Janeiro, 2003.

\section{ASSOCIAÇÃO BRASILEIRA DE NORMAS TÉCNICAS. NBR NM 52: agregado miúdo: determinação da massa específica e massa aparente. Rio de Janeiro, 2009a.}

\section{ASSOCIAÇÃO BRASILEIRA DE NORMAS} TÉCNICAS. NBR NM 53: agregado graúdo: determinação da massa específica, massa aparente e absorção de água. Rio de Janeiro, 2009b. 
ASSOCIAÇÃO BRASILEIRA DE NORMAS TÉCNICAS. NBR NM 67: concreto:

determinação da consistência pelo abatimento do tronco de cone. Rio de Janeiro, 1998.

CALLISTER JÚNIOR, W. D.; RETHWISCH, D. G. Ciência e Engenharia dos Materiais: uma introdução. 9.ed. Brasil: LTC. 2016.

CATÓIA, T. Concreto Ultraleve Estrutural com Perolas de EPS: caracterização do material e estudo de sua aplicação em lajes. São Carlos, 2012. 154 f. Tese (Doutorado em Engenharia Civil) - Escola de Engenharia, Universidade de São Paulo, São Carlos, 2012.

COMITÉ EURO-INTERNATIONAL DU BÉTON AND FÉDÉRATION INTERNATIONALE DE LA PRÉCONTRAINTE. Lightweight Aggregate Concrete: manual of design and technology. London: The Construction Press, 1977.

COOK, D. J. Expanded Polystyrene Beads as Lightweight Aggregate for Concrete. Precast Concrete, v. 4, n. 12, p. 691-693, 1973.

DE LARRARD, F. Concrete Mixture Proportioning: a scientific approach. Londres: E\&FN SPON, 1999. (Modern Concrete Technology Series, v. 9).

DEMIRBOGA, R.; KAN, A. Thermal Conductivity and Shrinkage Properties of Modified Waste Polystyrene Aggregate Concretes. Construction and Building Materials, v. 35, p. 730-734, 2012.

DEMIREL, B. Optimization of the Composite Brick Composed of Expanded Polystyrene and Pumice Blocks. Construction and Building Materials, v. 40, p. 306-313, 2013.

FERRÁNDIZ-MAS, V.; GARCÍA-ALCOCEL, E. Physical and Mechanical Characterization of Portland Cement Mortars Made with Expanded Polystyrene Particles Addition (EPS). Materiales de Construcción, v. 62, n. 308, p. 547-566, 2012.

FORMAGINI, S. Dosagem Científica e Caracterização Mecânica de Concretos de Altíssimo Desempenho. Rio de Janeiro, 2005. 259 f. Tese (Engenharia Civil) - Universidade Federal do Rio de Janeiro, Rio de Janeiro, 2005.

GONÇALVES, P. J. S. Emprego de EPS

Reciclado em Blocos Vazados de Concreto para Otimização do Conforto Térmico das Edificações. Manaus, 2018. 147 f. Dissertação (Mestrado em Engenharia Civil) - Universidade Federal do Amazonas, Manaus, 2018.
HERNÁNDEZ-ZARAGOZA, J. B. et al. Cellular Concrete Bricks with Recycled Expanded Polystyrene Aggregate. Advances in Materials Science and Engineering, v. 2013, 2013.

KAYA, A.; KAR, F. Properties of Concrete Containing Waste Expanded Polystyrene and Natural Resin. Construction and Building Materials, v. 105, p. 572-578, 2016.

KRÜGER, E. L. et al. Thermal Analysis of WoodCement Panels: heat flux and indoor temperature measurements in test cells. Construction and Building Materials, v. 23, p. 2299-2305, 2009.

LING, I. H.; TEO, D. C. L. EPS RHA Concrete Bricks: a new building material. Jordan Journal of Civil Engineering, v.7, n. 4, p. 361-370, 2013.

LIU, N.; CHEN, B. A Novel Lightweight Concrete-Fabrication and Its Thermal and Mechanical Properties. Construction and Building Materials, v. 44, p. 691-698, 2013.

LIU, N.; CHEN, B. Experimental Study of the Influence of EPS Particle Size on the Mechanical Properties of EPS Lightweight Concrete. Construction and Building Materials, v. 68, p. 227-232, 2014.

MANDLIK, A. et al. Lightweight Concrete Using EPS. International Journal of Science and Research, v. 4, n. 3, p. 2007-2010, 2015.

MONTE, F. L.; BAMONTE, P.; GAMBAROVA, P. G. Physical and Mechanical Properties of HeatDamaged Structural Concrete Containing Expanded Polystyrene Syntherized Particles. Fire and Materials, v. 39, p. 58-71, 2015.

NEVILLE, A. M. Propriedades do Concreto. 5. ed. Bookman: Porto Alegre, 2016.

PEDRA, S. A. Potencialidades na Termografia Infravermelha Aplicada ao Design do Conforto Térmico de Alvenaria Estrutural. Belo Horizonte, 2011. 100 f. Dissertação (Mestrado em Design) - Escola de Design, Universidade do Estado de Minas Gerais, Belo Horizonte, 2011.

RIBEIRO, U. G. Desempenho Térmico, Acústico e Mecânico de Compósitos Cimentícios Produzidos com Resíduos da Indústria Madeireira de Porto Velho. Manaus, 2016. 76 f. Dissertação (Mestrado em Engenharia Civil) Escola de Engenharia, Universidade Federal do Amazonas, Manaus, 2016.

SARTORTI, A. L.Comportamento Dinâmico de Lajes Maciças de Concreto Leve com Pérolas de EPS. São Carlos, 2015. 251 f. Tese (Doutorado em Engenharia Civil) - Escola de Engenharia, Universidade de São Paulo, São Carlos, 2015. 
SAYADI, A. A. et al. Effects of Expanded Polystyrene (EPS) Particles on Fire Resistance, Thermal Conductivity and Compressive Strength of Foamed Concrete. Construction and Building Materials, v. 112, p. 716-724, 2016.

SOTO, N. T. A. Avaliação do Uso de Agregado de Resíduo de Construção Civil nas Propriedades do Concreto no slump para Fabricação de Artefatos de Concreto. Curitiba, 2017. 171 f. Dissertação (Mestrado em Engenharia Civil) - Escola de Engenharia, Universidade Tecnológica Federal do Paraná, Curitiba, 2017.

TANG, W.; CUI, H.; TAHMASBI, S. Fracture Properties of Polystyrene Aggregate Concrete After Exposure to High Temperatures. Materials, v. 9, n. 630, 2016.

TANGO, C. E. S. Blocos de Concreto: produção, dosagem e controle de qualidade. A Construção, n. 1890, p. 11-18, 1984.

TANGO, C. E. S. Fundamentos de Dosagem de Concreto Para Blocos Estruturais. In:

INTERNATIONAL SEMINAR ON

STRUCTURAL MASONRY FOR

DEVELOPING COUNTRIES, 5., Florianópolis, 1994. Proceedings... Florianópolis, 1994.
TRUSSONI, M.; HAYS, C. D.; ZOLLO, R. F. Comparing Lightweight Polystyrene Concrete Using Engineered or Waste Materials. American Concrete Institute Materials Journal, v. 109, n. 1, p. 101-107, 2012.

VIEIRA, R. K. et al. Optimization of Expanded Polystyrene Lightweight Aggregate in Pre-Cast Concrete Blocks by a Completely Random Experimental Design (CRED) with Mixture and Process Variables. Open Journal of Statistics, v. 6, p. 594-604, 2016.

XU, Y. et al. Experimental Study and Modeling on Effective Thermal Conductivity of EPS Lightweight Concrete. Journal of Thermal Science and Technology, v. 11, n. 2, 2016.

XU, Y. et al. Mechanical Properties of Expanded Polystyrene Lightweight Aggregate Concrete and Brick. Construction and Building Materials, v. 27, p. 32-38, 2012.

\section{Paulo Gonçalves}

Programa de Pós-Graduação em Engenharia Civil | Universidade Federal do Amazonas | Av. Rodrigo Otávio, 6200| Manaus - AM - Brasil | CEP 69080-900 | Tel.: (92)3305-1480 | E-mail: paulo_simaogoncalves@outlook.com

\section{Raimundo Vasconcelos}

Programa de Pós-Graduação em Engenharia Civil | Universidade Federal do Amazonas | E-mail: vasconcelos@ufam.edu.br

Revista Ambiente Construído

Associação Nacional de Tecnologia do Ambiente Construído

Av. Osvaldo Aranha, 99 - 3o andar, Centro

Porto Alegre - RS - Brasil

CEP $90035-190$

Telefone: +55 (51) 3308-4084

Fax: +55 (51) 3308-4054

www. seer. ufrgs. br/ ambienteconstruido

E-mail: ambienteconstruido@ufrgs.br 